Portland State University

PDXScholar

\title{
Intercultural training and international exchange : an exploratory study of the association of intercultural training with hosting goals of American families
}

Jan Marie Oehlschlaeger

Portland State University

Follow this and additional works at: https://pdxscholar.library.pdx.edu/open_access_etds

Part of the Bilingual, Multilingual, and Multicultural Education Commons, and the International and Intercultural Communication Commons Let us know how access to this document benefits you.

\section{Recommended Citation}

Oehlschlaeger, Jan Marie, "Intercultural training and international exchange : an exploratory study of the association of intercultural training with hosting goals of American families" (1989). Dissertations and Theses. Paper 3897.

https://doi.org/10.15760/etd.5781

This Thesis is brought to you for free and open access. It has been accepted for inclusion in Dissertations and Theses by an authorized administrator of PDXScholar. Please contact us if we can make this document more accessible: pdxscholar@pdx.edu. 
AN ABSTRACT OF THE THESIS OF Jan Marie Dehlschlaeger for the Master of Science in Speech Communication presented March 9, 1989.

Title: Intercultural Training and International Exchange: An Exploratory Study of the Association of Intercultural Training with Hosting Goals of American Families.

APPROVED BY THE MEMBERS OF THE THESIS COMMITTEE:

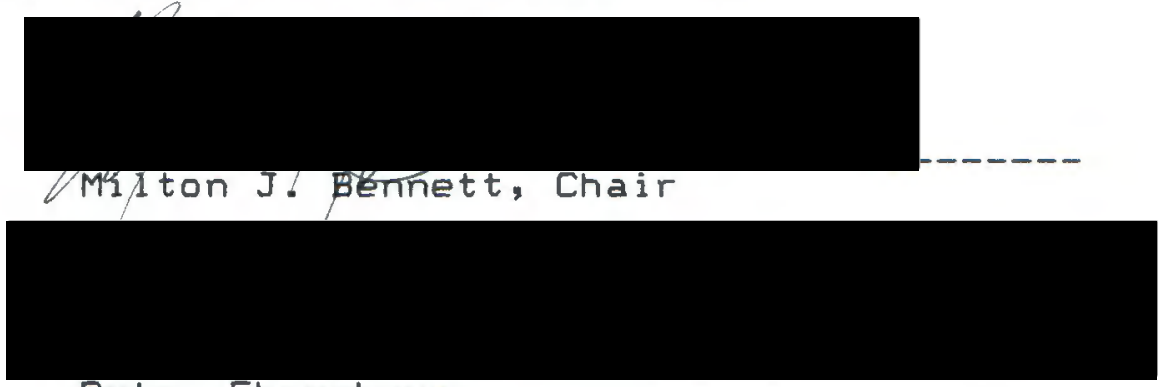

Peter Ehrenhaus

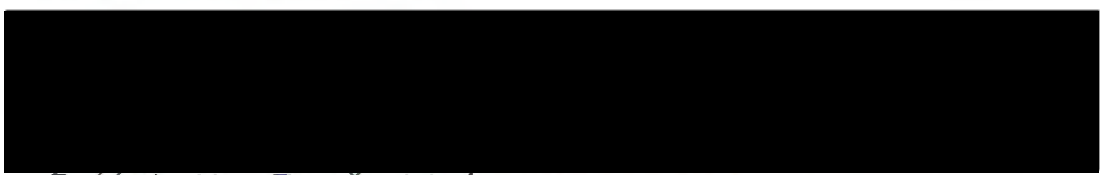

Jajpet M. Bennett

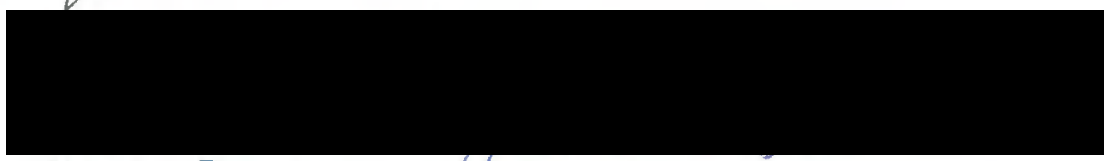

Nancy Benson

This study investigated the host family experience, specifically examining the goals of host families and intercultural training of host families. It compares the the importance and accomplishment of goals between interculturally trained host families and untrained host 
families. The focus of the research addressed the following research questions:

1) Do host families who receive intercultural training rate their goals differently than families who do not receive intercultural training?

1a) Do host families who receive intercultural training rate differently the goals in which the student meets intra-family needs than families who do not receive intercultural training?

2) Do host families who receive intercultural training report the level of accomplishment of their goals differently than host families who do not receive intercultural training?

2a) Do host families who receive intercultural training report the level of accomplishment of goals regarding cultural awareness differently than families who do not receive intercultural training?

3) To what extent is there a relationship between trained host family ratings of importance and ratings of accomplishment of goals?

3a) To what extent is there a relationship between untrained host family ratings of importance and ratings of accomplishment of goals?

The study used a quasi-experimental design. Subjects were 55 families who hosted Japanese students for three to four weeks as part of of INTRAX (International Training and Exchange). Twenty-four of the families 
received four hours of intercultural training. Eighteen trained host families and twenty untrained host families completed the Fisher-Moore (1989) Host Family Goals Questionnaire after the international student left the host families' homes.

The results of the study show that ten goals hold a high degree of importance and nine goals were rated to be highly accomplished by both trained and untrained host families. However, the study clearly shows that there was virtually no significant statistical difference between trained and untrained host families concerning the importance or the level of accomplishment of goals. Neither did intra-family or cultural awareness goals show a difference within each of the two groups, but both groups reported that goals which emphasized cultural awareness were rated overall to be more important. Exploring the association of importance and accomplishment within each of the host family groups, untrained host families showed a stronger relationship between goal importance and the reported level of goal accomplishment. Looking specifically at the ten goals which both groups rated to have high importance, both groups reported a substantial association between goal importance and the level of goal accomplishment. overall, the study does not support that there is an association between intercultural training and the importance and accomplishment of host family goals. 
INTERCULTURAL TRAINING AND INTERNATIONAL EXCHANGE: AN EXPLORATORY STUDY OF THE ASSOCIATION OF INTERCULTURAL TRAINING WITH HOSTING GOALS OF AMERICAN FAMILIES

by JAN MARIE OEHLSCHLAEGER

A thesis submitted in partial fulfillment of requirements for the degree of

\author{
MASTER OF SCIENCE \\ in \\ SPEECH COMMUNICATION
}

Portland State University

1989 
TO THE OFFICE OF GRADUATE STUDIES:

The members of the Committee approve the thesis of Jan Marie Oehlschlaeger presented March 9, 1989.

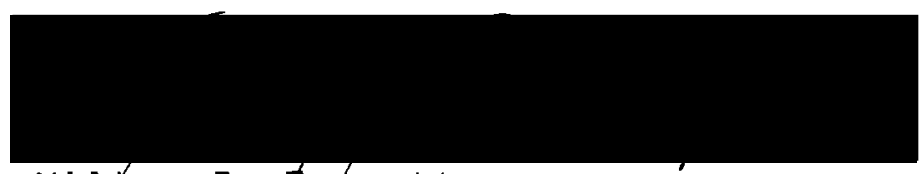

Milton J. Bennett

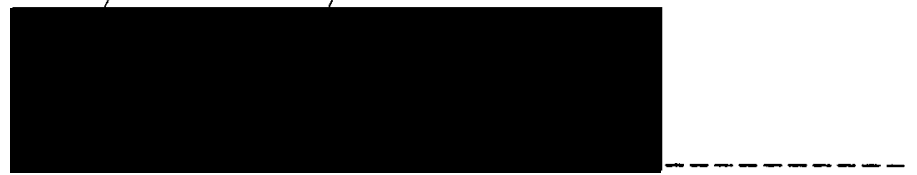

Peter Ehrenhaus

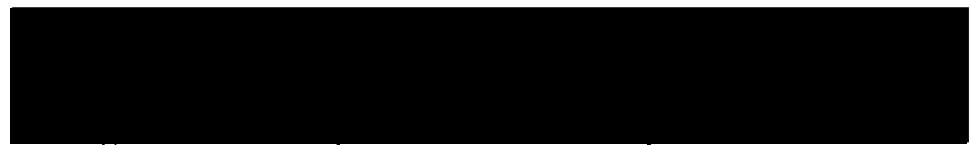

Japet M. Benifett



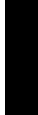

Nancy Benson

APPROVED :

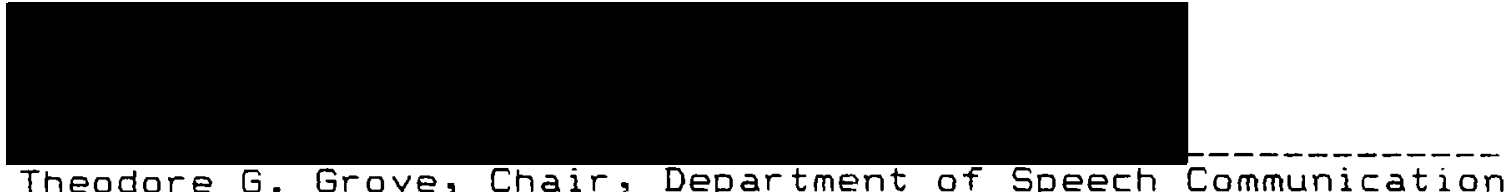

Bernard Ross, Vice Provost for Graduate studies 


\section{ACKNOWLEDGEMENTS}

Role models seem to often unexpectedly appear in one's life. And individuals who project more than an image but also motivate and expend time developing another's understanding and skills are rare. For these reasons I acknowledge Drs. Milton and Janet Bennett. Thanks for your on-going enthusiasm, supportiveness, and earnestness towards intercultural communication training.

Other individuals played a significant role in the completion of my research. Deborah Fisher-Moore discovered our common interest in researching intercultural contact, Drs. Peter Erhenhaus and Theodore Grove responded to endless questions concerning statistical analysis, and Dr. Nancy Benson added final touches to my manuscript. And most significant were friends and family who saw me through another project.

Finally, encouragement to pursue the next challenge often derives from a mystical paradox. So I dedicate this to Ed, whose absence motivated me to excell, and whose presence inspires me to celebrate fulfillment. 
TABLE OF CONTENTS

PAGE

ACKNOWLEDGEMENTS . . . . . . . . . . . . . . . . . . . . i i LIST OF TABLES . . . . . . . . . . . . . . . . . . . . . vi

\section{CHAPTER}

I INTRODUCTION

Purpose and Literature Review . . . . . 1

Summary . . . . . . . . . . . . 13

Research Questions........... 14

Definition of Terms . . . . . . . . 15

Format................ 17

I I STATEMENT OF DESIGN . . . . . . . . . . . . 19

Purpose . . . . . . . . . . . . . 19

Methods and Techniques . . . . . . . . . 19

Summary . . . . . . . . . . . . . . . . 31

I I I RESULTS AND DISCUSSION . . . . . . . . . . . 33

Importance of Goals . . . . . . . . . . . 33

Accomplishment of Goals . . . . . . . 41

Association of Goals and Intercultural

Training... . . . . . . . . 46

Summary . . . . . . . . . . . 52 
IV CONCLUSION, LIMITATIONS AND DIRECTIONS FOR

FUTURE RESEARCH . . . . . . . . . . . . . . 54

Implications for Host Family Programs . . . 54

Implications for Intercultural Training of Host Families.... . . . . . . . 56

Limitations of the Study . . . . . . . 57

Directions for Future Research . . . . . 62

REFERENCES CITED . . . . . . . . . . . . . . . . . . . . . . 68

APPENDIX A

APPENDIX $\mathrm{B}$. . . . . . . . . . . . . . . . . . . . . . . . . 86 


\section{LIST OF TABLES}

TABLE

PAGE

I Mean Ratings of Goal Importance by Trained

and Untrained Groups . . . . . . . . . . 34

I I Comparative Ratings of Most and Least Important

Goals by Trained and Untrained Host Families. 40

II Mean Ratings of Goal Accomplishment by Trained and Untrained Groups . . . . . . . . . . 42

IV Comparative Ratings of Most and Least Accomplished

Goals by Trained with Untrained . . . . . . 47

$\checkmark$ Pearson Correlation Coefficients between Importance and Accomplishment of 43 Hosting Goals for

Trained and Untrained Host Families. . . . . 49

VI Pearson Correlation Coefficients between Importance

and Accomplishment of the Most Important

Hosting Goals for Trained and Untrained Host

Families . . . . . . . . . . . . . 50

VI Mean Ratings of Most Important Goals Contrasted

Among Urban and Rural Host Family Groups . . 65 


\section{CHAPTER I}

INTRODUCT ION

\section{PURPOSE AND LITERATURE REVIEW}

Since World War II millions of youth and host family members have exchanged the pleasure and challenge of establishing interpersonal friendship. This world-wide educational endeavor captivates the attention of research, but most of it is directed toward the experience of the sojourner, not the host family.

Systematic research describing the general nature of the host family experience has been lacking in the field at large (Grove, 1984). Little effort has been focused towards understanding the goals of host families, the impact of intercultural contact upon host families, or the effect of intercultural training upon host families.

The purpose of this thesis is to further investigate the host family experience. It specifically examines the goals of host families and intercultural training of host families by examining the extant literature on intercultural exchange and, utilizing a quasi-experimental design, reports on the comparison of goals between interculturally trained host families and untrained host families. 
In the following pages of this chapter, the I iterature which discusses intercultural exchange will be reviewed for the purpose of establishing a basis to conduct exploratory research. The literature is divided into four sections: 1) goals, 2) intercultural contact,

3) necessity of intercultural training, and 4) format of intercultural training.

\section{Gㅡㅁaㅡㄴㅗㅗ}

One commentator (Rhinesmith, 1985) has identified the goals of international exchange as 1 ) international understanding for peace, 2) acquisition of skills and knowledge, and 3) the transfer of technological and professional expertise. Kelman (1962) further contends that international exchange proposes to create goodwill. Torrey and Wheeler (1988) also support that host families, as perceived by $80 \%$ of agencies, participate in order to act as goodwill ambassadors and to gain foreign exposure. However, Fisher-Moore (1989) questions whether the underlying assumption is warranted that these established goals are relevant for both the sojourner and the host family. She is currently exploring what goals and priorities host families hold, and if these goals and priorities are reflective of the exchange goals expressed in 1 iterature.

The literature on the goals of host families is ambiguous. An investigation of goals from the host family 
perspective will identify the reasons for their participation in international exhange.

\section{Intercuㅣturgal oㅡtㅡㅁㅡ}

Several researchers concur that intercultural contact

has an impact upon the host. Paige (1983) states:

The almost exclusive concern with the effects of the dominant culture upon the sojourner has led most theoreticians and researchers to ignore the reverse side of the intercultural contact equation: the influence of the sojourner upon the host culture. ( $p .102$ )

Directing attention only to the sojourner neglects an exploration of the extensive impact that intercultural representatives create upon the host community. Bochner

(1982) exhorts researchers to adopt a systematic approach to contact phenomenon. We should ask, "To what extent, if any, has the host community changed?" ( $p$. 24). Unidirectional

research towards the newcomer discounts that those individuals also impact their surroundings.

However, Brislin (1981) stresses that not all

intercultural contact reduces hostility or develops favorable attitudes. Pool (1965) agrees:

But there is good reason to suspect that the net impact of the ordinary traveler on his host, like the impact of his host on the traveler, is primarily to increase the complexity and differentiation of the images held. The consequence is undoubtedly sometimes favorable, sometimes regressive toward the middle, as well as sometimes unfavorable. (P. 119)

Hanvey (1979) also concurs in noting that contact does not automatically lead to understanding: "There must be 
readiness to respect and accept, a capacity to participate. That participation must be reinforced by rewards that matter to the participant" (p. 51 ).

Investigation of the impact of intercultural contact on host families has been initiated by Lowe, Askling, and Bates (1984). They suggest four dimensions of impact: 1) increased interest and understanding in cultural differences, 2) formation of intimate relationships, 3) increased concern about world issues, and 4) host participation in national foreign affairs. These support the international exchange goals suggested by Rhinesmith (1985) which are stated earlier in this chapter. Paige (1983) also views intercultural contact as providing opportunities for intercultural communication and relations. He says:

From these opportunities can emerge new knowledge about oneself and others (cognitive learning), a higher level of global knowledge (cognitive learning), empathy and a greater appreciation of the aspirations of others (affective learning), and new behavioral repertoires for functioning in intercultural communication situations (behavioral learning). (p. 106)

Acknowledging that contact does create impact, intercultural researchers cite the significance of international exchange. One issue surfaces: contact does not assure mutual understanding.

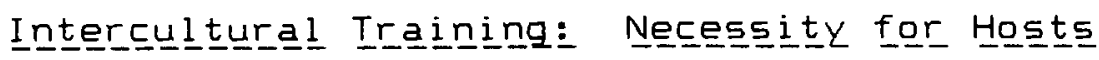

The field of cross-cultural training is formally less than 20 years old (Martin, 1986). However, the 
significance of intercultural training is stated by Josef Mestenhauser:

In addition we believe that orientation should be discussed within an international context, because the participation of foreign scholars is crucial to the orientation of their nationals before coming to the U.S. and to the orientation of U.S. students before going to travel, study, and work in their countries. (cited in Martin, $1986, \mathrm{p} .103$ )

Recognizing the need for intercultual orientation for sojourners is firmly established. However, the literature on this topic reveals that little research has explored the effect of training the host.

Several authors and agencies nevertheless affirm the practice of extending training to host communities. For instance, Triandis (1977) directs attention to the question of who should be trained--only the visitor or also his/her counterparts?

Following this line of thought, one of the key assertions of the Youth Exchange Homestay Study for the United States Information Agency is that orientation, preparation, and ongoing support are vital to quality homestays (Torey \& Wheeler, 1988). The unique resource,

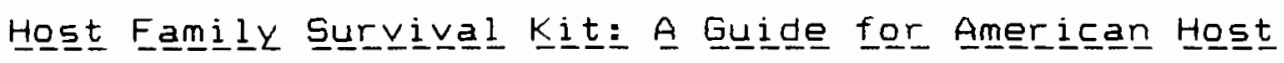
Fami $\underline{\text { I }}$ ie日s, reinforces the need of orientation for host families (King \& Huff, 1985). Among a list of questions that are proposed for the host family to ask while selecting an exchange agency, guideline ten suggests the host family inquire whether special services are provided for hosts when 
deciding to host a student: "Are there orientation opportunities and literature to prepare the family and provide practical guidance?" (King \& Huff, 1985, P. 106).

The U.S. Information Agency (1983) prints regulations to be followed by programs who receive student J-Visa documentation through the government. This volume includes regulation number 8 (summarized):

Orientation for Hosts: Orientation must also be provided to host families in advance of the student's arrival. Each host family should be well briefed on the family and cultural patterns of the foreign student's country. Each family should also be apprised of potential problems in hosting and provided with suggestions on how to cope with normal adjustment problems. ( $P .21$ )

Pusch (1981) maintains that training is necessary in order to initiate contact with confidence and maintain insight and skill so both the person in transition and those he encounters will learn more, enjoy more, and pursue still deeper relationships. She addresses visitor involvement training:

Training for visitor involvement is designed especially for volunteers, including host families, community program coordinators, fieldwork placement personnel, and students who volunteer to assist new foreign students. volunteers learn and practice specific ways to enable foreign students and visitors to become constructively involved in activities, organizations, and families in their communities. (p. 75)

$$
\text { Grove (1982) states that there iE little }
$$

disagreement that host family members should receive an orientation program. As Director of Research for the 
American Foreign Service, International, he asserts that probably fewer than a majority of hosts actually participate in thorough or extensive sessions. Many hosts are merely sent a handbook which they may or may not read at their leisure. Such materials concentrate on practical and emergency procedures, smooth mutual adjustment of the family and student, and the intercultural learning benefits that are possible for the participating host family.

Grove and Hansel (1987) are currently updating an orientation document. A goal of their Integrated Orientation Project, originating in 1982 , is to develop a model orientation program that coordinates and interrelates the information provided to students, natural families, and host families. All phases of the homestay will be addressed: pre-departure, during-the-sojourn, and post-return. Again, the difficult aspect surfaced that many prospective hosts were unable or unwilling to attend sessions and thus required a modest-length training document be mailed to them.

An interactive educational and training format, the Intercultural Communication Workshop, is advocated by Scalzi and Spring (1975) to train host families. Specific objectives suggest using the workshop to improve "foreign student-host family relations" (p. 58 ).

The 1 iterature includes numerous assertions which support orienting and training host families. However, 
there is little research that explores to what extent intercultural training influences the host family experience.

\section{Intercoulturral Iraining: Format of Iraining}

This final section of the literature review provides a basis which clarifies the nature and content of intercultural training for host families. Janet Bennett (1986) suggests that the effective intercultural trainer clarifies the nature of training, examines the potentials and pitfalls of the training environment, and grounds the practice of training in theory. The following three facets are discussed to establish the nature, the content, and the theory of training: 1 ) training terminology, 2) training goals, and 3) training design.

In 1984 researchers and practitioners at the University of Minnesota initiated an evaluation of intercultural training. They hosted the conference, "Cross-cultural Orientation: Theories, Practices, Problems, and Solutions." Josef Mestenhauser, leader of these efforts, expressed the following objectives: to clarify what orientation means, how its activities should be sequenced, what outcomes should be presented, how programs should be coordinated, and who might best conduct certain types of programs (cited in Martin, 1986, P. 103).

Kohls (1987) and Bennett (1986) clarify what orientation means by distinguishing the terminology which is used in the intercultural field. According to 
Kohls, briefing is the most selective form of orientation whose purpose is to provide background in a concise and focused format. Batchelder (1978) defines orientation as that which proposes to acquaint with the existing situation or environment. Its aim, according to Kohls, is to orient a person to new circumstances or ideas by listing do's and don'ts and addressing survival phrases. Bennett succinctly characterizes orientation as the "who, what, when, and where." However, training pushes beyond and entertains the "how". It includes a skills approach, with the end goals involving behavior. objectives are stated and measured at the end of this practical, results-oriented learning. Bennett advocates that the "why" is addressed by the educational perspective. This equips the trainee not only to demonstrate skill, but to be able to reframe experience within new environments in order to pursue inquiry.

Paige and Martin (1983) describe training goals as "critical variables" because they affect the process and the effects of training. Vague, ambiguous goals do not provide the direction that is needed for effective training. They concur with Triandis (1977) that training addresses cognitive, affective and behavioral goals. CCognitive concerns analysis or the interpretation of occurring events; affective concerns the emotions which are elicited by 
particular external factors; and behavioral concerns the actual behavior that one performs.)

Training format incorporates two components:

1) content, culture-general vs. culture-specific (Triandis, 1977; Bennett, 1986) and 2) process, experiential vs. intellectual models (Bennett, 1986). Bennett delineates which approaches address each of these components:

-Orientation addresses the cognitive and behavioral, includes culture-specific, and utilizes the intellectual process.

- Training addresses the affective and behavioral; includes culture-specific, and utilizes the experiential process.

-Education addresses the cognitive, affective, and behavioral, includes culture-specific and culturegeneral, and utilizes the experiential and intellectual processes. ( $p .121$ )

Bennett (1986) summarizes the body of literature which includes the following five training models: intellectual, area training, self-awareness, cultural awareness, and multidimensional model. She devised the "Intercultural Programming Grid' which maps different training approaches. Assuming that all training attempts behavioral goals, her grid focuses on two questions: "Does the program focus on culture-general or culture-specific goals?" and "Does the program attempt primarily cognitive or affective goals?" (pp. 129-30). Her design is congruent with Triandis' (1977) conceptual frame of training which emphasizes cognitive, affective, and behavioral goals and differentiates culture-general from culture-specific. 
The strength of Bennett's grid is the categorization of training events. It offers a model for devising intercultural training. Bennett explains:

-Programs which have as their primary focus culture-specific content and affective goals are placed in Quadrant $A$, and include area simulations, bicultural workshops, and culturespecific events.

-Programs which have culture-specific content, but primarily cognitive goals are placed in Quadrant B, and include assimilators, university models, Kraemer's cultural self-awareness, language learning, and area studies conceptual models.

-Programs placed in quadrant C stress affective goals and culture-general content and include T-groups, role-plays, culture-general ICW's, and culture-general simulations.

-Programs placed in quadrant D stress cognitive goals and culture-general content and include intercultural communication courses, culturegeneral curriculum, and "learning how to learn" methodology. (p. 130$)$

Bennett advocates that by carefully planning content and process while balancing affective and cognitive goals and integrating culture-general with culture-specific, a trainer effectively equips intercultural learners.

Paige and Martin (1983) underscore the importance of the trainer utilizing an informed scheme of sequencing the training activities. They differentiate each learning activity according to its demand of behavioral requirement, its learning domains, and the degree of personal risk associated with the activity. Cognitively-oriented and lower personal risk activity precede the affective, 
behavioral and higher risk events. Paige and Martin (1983) maintain that debriefing training is just as critical as goal planning. It connects the learning event and the participant's reactions to a conceptual perspective. Four objectives of debriefing are: to minimize rationalization of behavior, to reduce negative emotional responses, to reduce resistance to learning, and to assist understanding and application. Debriefing must be facilitated when cognitive orientations are challenged, affective learning is encouraged and new values are brought to awareness.

Bennett (1985) suggests that an example of a cultural awareness training model cone of the five models reviewed by Bennett) is the Intercultural Workshop. Clarke (1971) designates the goals of this training format:

While cultural awareness, or awareness of cultural differences in terms of values, customs, and behaviors which affect human relations, is a principal aim of the workshop, it is also concerned with understanding the effects of these differences on intercultural communication and cross-cultural relations ... a ims to stimulate respect for and appreciation of cultural differences as valuable in themselves and as the starting point for communication rather than barriers. (cited in Pedersen and Hoopes, 1975, p. 90)

Bennett (1985) summarizes the workshop's goals as recognition of cultural differences, analysis of the role of values in communication, appreciation of differences, and improvement of intercultural problem-solving skills.

Brislin, Landis, and Brandt (1983) list ten empirical studies which research the effects of intercultural training, 
categorizing them as cognitive, affective, or behavioral. Cognitive results included understanding of host country, decrease in stereotypes about hosts, complex thinking about cultures, and an increase in world-mindedness. Affective changes in reactions were associated with greater enjoyment with hosts and good working relationships. Finally, changes in people's behavior resulted in better interpersonal relationships, better adjustment to life, greater ease interacting with hosts, and setting and achieving goals for interpersonal relationships with hosts.

This review offers a basis for designing format training. Bennett's grid and Triandis' training components identify which training activities will offer a complete process of learning issues. Paige and Martin outline the effective sequencing of training activites. More specifically, The Intercultural Workshop embraces the development of cultural awareness which is endorsed as a training program goal by Pusch (1981).

\section{SUMMARY}

Intercultural exchange literature lists perceived goals and states that intercultural contact has an impact on both the sojourner and the host. It also supports training the intercultural sojourner.

However, goals of host families have not been investigated. Nor has intercultural training for host 
families been examined. Given the likelihood that the impact of intercultural contact may be both negative and positive, depending upon conditions of both situational and personal nature (Amir \& Garti, 1977), intercultural training merits consideration for both the host and the international guest.

This study proposes to further the investigation of the host family experience. It focuses on the goals of American host families and intercultural training for American host families.

The following section presents the research questions which this study addresses.

\section{RESEARCH QUESTIONS}

The purpose of this thesis is to 1) investigate the importance and accomplishment of goals of host families and to 2) explore if there is an association between host family goals and intercultural training.

The following research questions provided the focus for this study:

1) Do host families who receive intercultural training rate their goals differently than families who do not receive intercultural training?

1a) Do host families who receive intercultural training rate differently the goals in which the student 
meets intra-family needs than families who do not receive intercultural training?

2) Do host families who receive intercultural training report the level of accomplishment of their goals differently than host families who do not receive intercultural training?

2a) Do host families who receive intercultural training report the level of accomplishment of goals regarding developing cultural awareness differently than families who do not receive intercultural training?

3) To what extent is there a relationship between trained host family ratings of importance and ratings of accomplishment of goals?

3a) To what extent is there a relationship between untrained host family ratings of importance and ratings of accomplishment of goals?

\section{DEFINITION OF TERMS}

Five terms are central to this paper, necessitating definition. They are homestay, host family, intercultural training, cultural awareness, and intra-family needs.

1. Homestay: full-time residence by a sojourner in the home of a host family. A sense of being completely immersed in the culture develops as the visitor is considered by the host family members to be an actively 
functioning member of their family lsee Grove \& Hansel, 1987). King and Huff (1985) distinguish the homestay visitor as someone different from a boarder, houseguest, visiting neighborhood friend, or live-in help. Participating in the family's normal day-to-day activities and discussions, the visitor learns about the family's values, beliefs, outlook, and historical roots. Over time and with continued involvement, the visitor usually develops a strong friendship with family members, a relationship of deep caring, and high mutual regard. The experience continues for a significant duration of time, from three weeks to as long as a year (Grove \& Hansel, 1987; Lowe, Askling, \& Bates, 1984).

2. Host Family: national families who provide room and board to international individuals for the purpose of cultural and interpersonal exchange (King \& Huff, 1985 ). Representing a cross-section of occupations, income levels, ethnic groups and ages, host families may or may not have children living at home. Grove (1981) confirms the variety of the demographic characteristics of host families, "They are located in medium-sized cities, affluent suburbs, small towns, and isolated rural areas" (P. 3 ).

3. Intercultural Training: Pusch (1981) states:

In any case, the purpose of a cross-cultural training program is to provide a "functional awareness" of the cultural dynamic present in intercultural relations and assist trainees in becoming more 'effective' in cross-cultural situations. Therefore, learning must occur at 
more than an intellectual level and skills must be practiced so they become a practical

resource for the trainees. ( $p .73$ )

In addition, Bennett (1986) specifies that a trainer must carefully build an intercultural training program: content must be balanced with process, culture-specific balanced with culture-general, and cognitive balanced with affective.

4. Cultural Awareness: "...awareness of cultural differences in terms of values, customs, and mores which affect human relations" (Clarke and Hoopes, 1975, p. 61). Cultural awareness training is invaluable in all training programs because it increases trainees' consciousness of the influence of culture on thinking and behaving (Pusch, 1981). It is designed not only for cultural self-awareness but also for understanding the inherent perceptual systems which influence the thinking and acting practiced by cultures.

5. Intra-family Needs: a generic term which refers to goals that address strengthening the family relationship regardless of the fact that the guest is an intercultural representative. An example of an intra-family need is "To strengthen our marriage."

\section{FORMAT}

The format for this thesis consists of the following four chapters: 
Chapter I presents an introduction to the thesis which includes the purpose of the study, the research questions, definition of terms, and this format. The content and methodology of the intercultural training conducted for host families is also introduced through a review of relevant literature in this chapter.

Chapter II presents the quasi-experimental methodology including a description of the questionnaire. The design of the study, methods of analysis, and training format are discussed.

Chapter II presents and discusses the study's results of frequency tests, T-testing, and Pearson Product-Moment Correlation.

Chapter IV presents a conclusion which discusses the implications and limitations of this thesis. 
CHAPTER I I

STATEMENT OF DESIGN

\section{PURPOSE}

As stated in Chapter One, the purpose of this study is to investigate the host family experience. Specifically, this study focuses on goals of host families and the impact of intercultural training on host families. The selected literature was researched to establish the goals and to establish training methods.

This study's research proposition asserts that goals of interculturally trained host families differ from goals of untrained host families. Secondly, it asserts that goal accomplishment of interculturally trained host families differs from goal accomplishment of untrained host families. The study utilizes a quasi-experimental design.

\section{METHODS AND TECHNIQUES}

\section{Resegarch Dessign}

This study employed the static-group comparison, a form of pre-experimental design (Campbell \& Stanley, 1963). A group of host families who received intercultural training was compared with a group of host families who did not receive training. Randomization was not possible with 
these pre-selected and available groups. Therefore, association patterns were explored, not causal relationships. The research questions 1 isted in Chapter I direct attention toward investigating if there is an association between intercultural training and host families" perceived importance of their goals and their perceived level of accomplishment of their goals.

T-tests were used to assess differences between the two groups by testing how each group differed in perceiving goal importance and accomplishment. The significance level was set at .01. This more conservative level was set recognizing that running tests on 43 variables risks obtaining false positives. Pearson Product-Moment Correlation was used to assess to what degree intercultural training interrelated with perceived importance and accomplishment of goals.

\section{Participipants}

Subjects for this study consisted of American host families who opened their homes to Japanese students as part of INTRAX (International Training and Exchange). The host families were recruited by two program coordinators-neither of whom had previously directed a homestay program. Both programs were held within the Portland-Beaverton, Oregon, vicinity. Each group held conversational English classes in the mornings, arranged sight-seeing opportunites three times each week, conducted 
a logistical-information pre-briefing, distributed an orientation booklet, and concluded the homestay with an evening säyongorag party. None of the host families recejved remuneration for the exchange.

The first program included 20 families, recruited by a coordinator who utilized neighborhood contacts, community newspaper ads and bulletin boards, community college and high school newsletters, and church bulletins. The families hosted female Japanese high school students for three weeks. These host families did not receive intercultural training. During the homestay, the hosts received a weekly memo to remind them of logistical details.

The second program included 30 families, recruited by a coordinator who contacted four church communities. They hosted male or female Japanese college students for four weeks. Each family was contacted weekly by phone for trouble-shooting and received a brief newsletter from the coordinator advising of logistical reminders and selected student-family scenarios. Throughout the homestay, much family interchange occurred. Families consistently invited one of the other Japanese students on their family-guest outings.

Twenty-four of the families from the second program participated in four hours of intercultural training. These subjects were classifed as the trained group. The untrained group consisted of $s i x$ families from the second program and 
all twenty families from the first program who did not attend the training session.

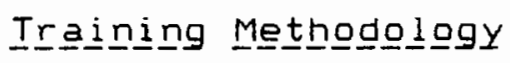

This researcher developed and conducted the intercultural training program for the host families, basing it on the training literature summarized earlier. Bennett's (1986) Intercultural Programming Grid states cognitive, affective, and behavioral goals that were addressed during the training. Paige's and Martin's (1983) sequential training theory determined the multidimensional approach (Bennett, 1986) to the four hour training session. The Intercultural Workshop (Clarke, 1971 \& Bennett, 1985) training format provided material and training exercises. The seven sections of the training program are described below.

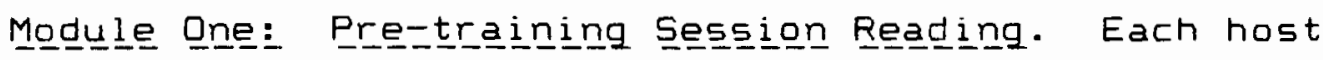
family received, two weeks in advance of the training session, two articles to read. Barna's (1985) article, "Stumbling Blocks in Intercultural Communication," discusses the intercultural concept that acknowledgement of difference is a prerequisite for intercultural understanding. Barna proposes to equip intercultural learners to identify and develop an appreciation of difference--an unsettling dynamic which counters embracing similarity. Similarly, the article by Stewart, Danielian, and Foster (1969), "Cultural Assumptions and Values", begins to orient the 
trainee to anticipate a hidden, little publicized, orientation which affects how individuals perceive the world. The article also draws the reader's attention to how they differ in these perspectives which are steeped in the values that their culture dominantly shapes.

This module addresed culture-general, cognitive goals and sequentially ranks as a low risk training activity, using the intellectual process.

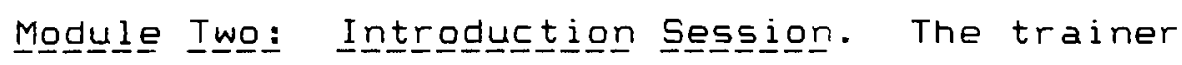
established an environment in which participants could begin to develop trust with one another and the training facilitator. The host families introduced themselves and expressed either one goal-oriented item that they especially held for the upcoming homestay or one anxiety-producing issue. This acquainted the facilitator with information that was utilized to connect host family perceptions and intercultural concepts during the training. The overall training schedule was presented and participants were invited to add any additional items they wanted to address during this session.

This second module primarily addressed affective goals by inviting participation in sharing and directing the training schedule. Cognitive, culture-general elements were addressed as the participants were told what the afternoon was going to include. Low to medium risk participation was involved during the experiential process. 


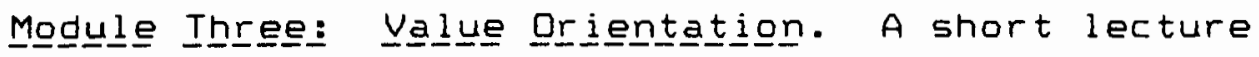
reviewed value orientations and ethnocentrism, both of which were discussed at length in the pre-training reading. The facilitator and an associate demonstrated an American/Contrast American role play. After this observational exercise, trainees were invited to state contrasting value orientations that they had identified, and later in the discussion they speculated on potential communication problems. The last segment of this module contrasted American-Japanese value orientations and briefly explored scenarios that host families and the Japanese student might experience because of differing values. Immediate application of training material increased the training session's credibility.

This third module focused on cognitive goals. Identifying the American value orientation as a mutual cause for communication misunderstanding, it also stimulated affective reflection. It began with a focus on culturegeneral material but expanded to both American and Japanese culture-specific. Participants experienced a low risk activity.

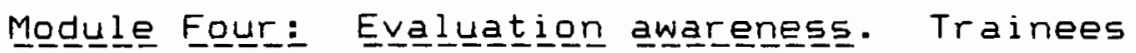
were shown unfamiliar Japanese artifacts and asked to comment on them. This exercise demonstrated the natural tendency individuals exhibit towards evaluating an object or action without first describing or interpreting it in context. This 
description-interpretation-evaluation exercise equipped the intercultural learners with a tool for interacting and reflecting upon the Japanese students' comments and behavior. Scenarios of host family-Japanese student encounters were examined which provided opportunity to apply this three step process.

Cognitive and behavioral goals implemented the design of this training session. Each trainee participated in the exercise, calling for medium risk-taking. Culture-specific application took priority.

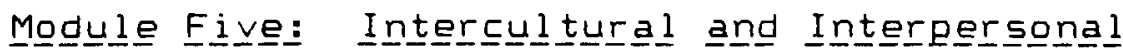

Sensitivity. A simulation which intertwined two cultures was facilitated. Each participant enacted one of the prescribed cultural task roles. The main objective of this exercise was to sensitize the American host families to respect the Japanese religious values, to become aware of culture shock, and to sense the significance and demanding effort of learning the language of another culture to enhance mutual communication. Debriefing played an integral part during this segment. Not only did it diffuse some negativity, but the debriefing connected intercultural understanding to sensitive interpersonal skills.

All three goals--affective, cognitive, and behavioral-were addressed during this high risk, experiential encounter. 
Culture-general material preceded culture-specific application.

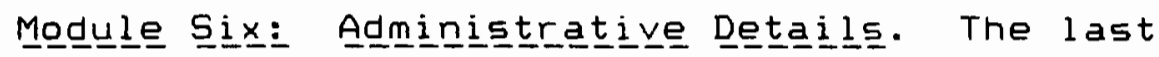
session of this training explained the exchange program logistics and answered many detailed questions raised by the host families. It gave the training facilitator opportunity to take on the role of program coordinator and clarify calendar items and the pronounciation of students' names.

This last interactive session primarily focused on cognitive goals, yet it also alleviated anxiety of host families who needed to know last minute details. It also shifted some responsibility to host families which gave them impetus to interact further with other hosts. It was purposefully formatted as a low risk, experiential activity to close the afternoon.

Moduuㅡㄹ Segven: Poost-trrainining Reagding. Culturespecific materials were distributed to the host families. The Japanese Culturgram, lists of suggested menu items, and a sheet of Japanese expressions were given to the hosts. These materials were prefaced with a remark that not all of this material was going to succinctly apply to each Japanese student. It was emphasized that these were simply guidelines to act as conversational prompters with the Japanese student.

The seven modules were designed to include the training methodolgy which intercultural training literature adovcates. The nature of the goals, the content of the 
material, and the process of the program were identified according to Bennett's Intercultural Programming Grid. Each module was carefully sequenced to align with Paige's and Martin's delineated risk level.

\section{Instrumentation}

The Fisher-Moore (1989) Host Family Goals Questionnaire (Parent/Guardian) was distributed to participating host families (see Appendix A). This evaluation questionnaire asked participants to assess the importance and accomplishment of forty-three possible hosting goals on anchored seven-interval scales with "one" indicating not important/not at all accomplished and "seven" indicating very important/accomplished to a great extent.

Example questions are illustrated:

As a host family member, how important was it for you:

To provide companionship for your child?

A) not important 1 2 3455 6 7 very important

To what extent was this accomplished?

B) not at all 125345 6 7 to a great extent

Fisher-Moore (1989) has examined the extent to which

goals stated in international exchange literature are congruent with host family goals. The questionnaire served as a measurement instrument in her study.

To address the specific concerns of the present study, the Fisher-Moore questions were organized into the two classifications of Cultural Awareness and Intra-family 
Needs. The reason for doing this was to explore a

possibility not found in the literature, which was that interculturally trained host families and untrained host families might rate differently the importance or the level of accomplishment of goals which addressed cultural awareness from those that addressed intra-family needs. The researcher did not feel there was enough evidence to assume directionality.

Intra-family goals included the questions (numbered according to the questionnaire):

\#5: bringing the family closer;

\#6: strengthening the host marriage;

\#7: experiencing parenting;

\#8: experiencing parenting a boy or girl;

\#9: re-establishing youth contact;

\#10: providing companionship for child/ren;

\#11: pleasing children who initiated hosting;

\#12: providing student as role model for children.

Each of these Intra-family Needs goals addresses strengthening the family relationship regardless of the fact that the guest is an intercultural representative.

Cultural Awareness goals included questions (numbered according to the questionnaire):

\#1: establishing a long-term relationship with someone from another culture;

\#2: having children interact with a representative of another culture; 
\#3: interacting with a representative of a specific culture;

\#4: sharing the family's lifestyle with someone from another culture;

\#23: having an educational experience by hosting;

\#24: achieving understanding of another culture;

\#28: sensitizing guest to own cultural identity;

\#34: changing family views of other cultures;

\#35: gaining guest's perception of America;

\#36: showing the good things about your values and the American way of life to an intercultural guest;

\#37: developing support for American politics;

\#39: having an intercultural experience;

\#40: increasing intercultural knowledge for the welfare of humanity;

\#41: increasing guest's intercultural knowledge for the welfare of humanity;

\#42: promoting international understanding and goodwill among the world as a contribution to peace.

Each of the Cultural Awareness goals denotes cultural difference as a dynamic component of the goal.

\section{Pr으드트므므토}

This researcher conducted all aspects of the research. The subjects were told that not only was the research to be used for a Master's degree thesis but that it could be used to revise host family orientation programs. It was verbally acknowledged and reiterated on paper that their responses would remain confidential and that in no way would their participation in completing the questionnaire influence 
their future involvement in exchange programs. Results of the research were guaranteed to be made available to families who indicated interest in receiving the information.

During each program's logistical pre-briefing meeting, the host families were told that after their hosting experience they would be invited to participate in research. Each volunteer would be given at the end of their hosting experience a questionnaire to complete, indicating hosting goals and perceived goal accomplishment. It was not mentioned to the untrained host audience that they would be compared to interculturally trained hosts.

Group $A$, trained host families, chose which of two training sessions they would attend. Each was four hours long and held on Sunday afternoon. Junior high and older children were invited to participate in the training. As stated before in this chapter, twenty-four families participated in the training. Group B, untrained host families, attended either a logistical-information pre-briefing or received the information in the mail. During the last two or three days of the hosting commitment, each program provided a sayononora party. Host families were invited to attend with the Japanese students. During each of these events, the researcher distributed the questionnaire to voluntary host family adults (children did not complete the instrument). Each 
participant signed an informed consent form and received a stamped and pre-addressed return envelope and a written set of instructions. During the following six weeks, $87 \%$ of the 74 distributed questionnaires were returned.

The questionnaire data were coded within two groups for statistical analysis. Group A consisted of host families of which both adults attended the intercultual training. Group B consisted of host families in either program of which both adults did not participate in the intercultural training sessions. Single parent and single adult host questionnaires constituted a host family unit in both groups. In order to maintain consistency in this research of the usage of the term 'host family', which refers to the family entity as a whole rather than to individuals of each family, spouses' questionnaire data were averaged and entered as a host family; single parent's or single adult's data were considered a host family unit. The advantages and disadvantages of this procedure are discussed in the Limitations section of Chapter Four.

\section{SUMMARY}

This exploratory study was pursued using the design of static-group comparison. Using the Fisher-Moore written questionnaire, the responses of interculturally trained host families were compared to untrained host families. The importance and accomplishment of goals were analyzed by 
t-tests. Pearson Product-Moment Correlation assessed the extent to which intercultural training and perceived importance and accomplishment of goals were interrelated. 


\section{CHAPTER I I I}

\section{RESULTS AND DISCUSSION}

The research design chosen to analyze the data focused on exploring the issues of whether there is a difference between the perceived importance and accomplishment of goals of interculturally trained and untrained host families, and whether there is an association between intercultural training and the perceived importance and accomplishment of host family goals. The data are presented in terms of the specific research questions.

\section{IMPORTANCE OF GOALS}

\section{R트느느노}

This portion of the study examines interculturally trained and untrained host families' ratings of importance of goals for participating in an intercultural exchange.

1. Do host families who receive intercultural training rate their goals differently than families who do not receive intercultural training?

Table I displays the means, standard deviations, and significance levels of difference for the trained and untrained host families' ratings evaluating the importance of the 43 goals stated on the questionnaire. Only one goal 


\section{TABLE I \\ MEAN RATINGS OF GOAL IMPORTANCE BY TRAINED AND UNTRAINED GROUPS}

Goal
Untrained Sig. Mean SD Level $\mathrm{N}=20$
1 Establish long-term relationship 4.690 .75

2 Children interact with guest

3 Interact with specific culture

4 Share family's lifestyle

5 Bring family closer

6 Strengthen marriage

7 Experience parenting

8 Experience parenting boy or girl

9 Re-establish child-youth contact

10 Companionship for children

11 Please children

12 Positive role model for children

13 Add to family income

14 Provide household help

15 Add childcare for own child

16 Establish travel contact

17 Develop personally

18 Develop family personally

19 Develop guest personally

20 Re-live exchange experience

21 Have fun

22 Satisfy hosting curiosity

23 Educate self

24 Understand another culture

25 Practice foreign language

26 Help guest learn English

27 Aid guest's ed. development

28 Sensitize guest to cul. identity

29 Learn about heritage

30 Share community hosting

31 Help program coordinator

32 Gain community self-recognition

33 Risk unpredictable challenge

34 Change family views of cultures

35 Get guest's percept'n of America

36 Show American values/way of life

37 Develop support for politics

38 Practice religious principles

39 Experience intercul. exchange

40 Get knowledge for human welfare

41 Guest's knowledge-human welfare

42 Promote intern'l goodwill/peace

43 Aid a less developed society
4.961 .56

5.001 .60

5.830 .89

3.811 .41

2.171 .13

$3.50 \quad 2.53$

$2.88 \quad 2.00$

2.83 1.86

$2.19 \quad 1.10$

$2.07 \quad 1.54$

2.671 .44

0.930 .26

$1.06 \quad 0.17$

$1.00 \quad 0.35$

$2.39 \quad 1.41$

4.691 .43

3.841 .73

5.710 .92

$1.64 \quad 1.21$

5.001 .25

$3.53 \quad 1.97$

5.470 .87

5.670 .96

$3.14 \quad 1.74$

$4.111 .6 \mathrm{~L}$

$4.75 \quad 1.72$

3.171 .26

1.080 .79

$3.64 \quad 1.77$

4.471 .65

$1.78 \quad 1.11$

4.031 .56

3.621 .59

$4.56 \quad 1.71$

5.031 .69

2.671 .36

6.170 .87

$5.56 \quad 1.07$

$4.50 \quad 1.45$

$4.56 \quad 1.24$

$4.75 \quad 1.56$

2.501 .96 $\begin{array}{lll}4.25 & 1.28 & .207\end{array}$

5.571 .29 .278

$\begin{array}{llll}4.73 & 0.97 & .520\end{array}$

$5.60 \quad 0.77 \quad .393$

4.111 .91 .616

$\begin{array}{llll}1.33 & 0.59 & .017\end{array}$

3.831 .92 .809

$2.63 \quad 1.62 \quad .787$

4.002 .83 .432

2.23 $1.59 \quad .947$

$\begin{array}{lll}1.96 & 1.85 & .895\end{array}$

$2.75 \quad 1.94 \quad .913$

$\begin{array}{llll}0.96 & 0.14 & .728\end{array}$

$\begin{array}{llll}1.05 & 0.22 & .894\end{array}$

1.000 .001 .00

$\begin{array}{llll}2.95 & 1.86 & .305\end{array}$

$\begin{array}{llll}3.95 & 1.69 & .154\end{array}$

3.921 .89 .901

$\begin{array}{lll}5.25 & 1.80 \quad .353\end{array}$

$3.44 \quad 2.85 \quad .075$

$5.35 \quad 1.34 \quad .412$

$3.081 .76 \quad .463$

$\begin{array}{llll}5.15 & 1.28 & .374\end{array}$

$5.40 \quad 1.21 \quad .459$

$2.90 \quad 1.63 \quad .664$

$\begin{array}{llll}3.85 & 1.96 & .658\end{array}$

$4.55 \quad 1.96 \quad .742$

$2.68 \quad 1.94 \quad .378$

$1.29 \quad 1.57 \quad .652$

$2.90 \quad 1.73 \quad .202$

$4.03 \quad 2.45 \quad .533$

$2.29 \quad 1.64 \quad .276$

$\begin{array}{llll}3.78 & 1.74 & .642\end{array}$

$\begin{array}{lll}3.95 & 2.27 & .615\end{array}$

$3.70 \quad 1.46 \quad .105$

$5.05 \quad 1.54 \quad .966$

2.451 .69 .669

$4.08 \quad 2.54 .002$

$\begin{array}{llll}5.73 & 1.12 & .637\end{array}$

$4.25 \quad 2.08 .680$

$4.20 \quad 2.08 \quad .532$

$\begin{array}{llll}4.38 & 1.96 & .521\end{array}$

$2.00 \quad 1.57 \quad .414$ 
"To put your religious principles into practice" (\#38) tested significant $(p=.002)$. The significance of this one difference is questionable, since it may reflect the religious disposition of host families recruited from church communities for one of the programs. Overall, the results strongly show that trained host families do not rate their goals differently than host families who have not received intercultural training.

1a. Do host families who receive intercultural training rate differently the goals in which the student meets intra-family needs than families who do not receive intercultural training?

The questionnaire included host family goals which addressed strengthening the family relationship regardless of the fact that the guest was an intercultural representative. Looking specifically at these goals which are 1 isted below as Intra-family, there is no difference indicated between trained and untrained host families in the ratings of goal importance. These goals included:

\#5: bringing the family closer;

\#o: strengthening the host marriage;

\#7: experiencing parenting;

\#8: experiencing parenting a boy or girl;

\#9: re-establishing youth contact;

\#10: providing companionship for children; 
\#11: pleasing children who initiated hosting; \#12: providing student as role model for children.

\section{Di 도ㄴㅡㅗㅗ으므}

Although there is no significant difference between the trained and untrained host families" ratings of goal importance, it is interesting to compare the highest and lowest ranked goals for both trained and untrained host families. The following discussion shows that there is a strong tendency to rank Cultural Awareness goals as important and a strong tendency to rank goals addressing Intra-family Needs lower in importance by both trained and untrained host families. Collapsing the data of the highest and lowest goals into the two groups of Cultural Awareness and Intra-family goals, t-tests report a significant $(p=.000)$ statistical difference between the means of the two groups of goals was found. Host families rate Cultural Awareness goals higher than goals which address Intra-family Needs. The following discussion explains the data supporting this finding.

Examining the goals that were reported as having the highest importance, 10 of the 43 were rated by either group to have a mean of nearly 5 or above on the anchored seveninterval scale in the questionnaire (see Table II). Examination of the data reveals the tendency in both groups of host families towards rating goals which emphasize cultural awareness at a higher level of importance. Seven of 
the ten goals rated as having greater importance emphasize cultural awareness; none of the ten goals address intra-family needs. The 10 goals of greater importance are listed below. The first seven goals represent the cultural awareness category.

\section{High-rated goals emphasizing Cultural Awareness:}

\#2: having children interact with a representative of another culture;

\#3: interacting with a representative of a specific culture;

\#4: sharing the family's lifestyle;

\#23: having an educational experience from hosting;

\#24: achieving understanding of another culture;

\#36: showing American values and way of life;

\#39: having a personal intercultural experience.

\section{Additional high-rated goals:}

\#19: furthering the guest's personal development;

\#21: having fun;

\#38: putting religious principles into practice.

Gverall, this finding begins to identify host family

goals that influence the reasons why American families participate in exchange programs. Chapter IV presents this finding as an area for further research and compares this study's findings with Fisher-Moore's (1989) concurrent host family goal research.

It is interesting to note that Bennett (1985) supports cultural awareness development as a highly rated goal 
for exchange participants. She demonstrates in her assessment of intercultural exchange goals within the Northwest Interinstitutional Council on Study Abroad consortium that "Understanding other cultures" rated as the most important goal for both agency and student participants alike. Participants acknowledged developing "Cultural self-awareness" as having third greatest significance. Intercultural exchange participants consistently rate highly the importance of goals which address cultural awareness. On the other end of the continuum, there is also an interesting commonality in the 18 of the 43 goals which were rated by either group to have a mean rating of 3 or less on the seven point scale presented in the questionnaire (see Table II). Six of these unimportant goals are classified by both groups as goals which meet intra-family needs; two are classified as emphasizing cultural awareness. Even one of the goals classified as cultural awareness, Goal \#37: "To develop friends and supporters for the American way of life by giving persons from other countries a better understanding of our political system", though marked as dependent upon cultural difference, could have been rated as having low importance because it was interpreted to invalidate or discount other cultures by promoting the American cultural perspective rather than celebrating cultural difference and awareness. The 18 goals which were rated as unimportant include: 


\section{Low-rated goals meeting Intra-fanily Needs:}

\#6: strengthening the host marriage;

\#8: parenting a boy or girl;

\#9: re-establishing youth contact;

\#10: providing companionship for children;

\#11: pleasing children who initiated hosting;

\#12: providing student as role model for children.

\section{Low-rated goals emphasizing Cultural Amareness:}

\#28: sensitizing guest to cultural identity;

\#37: developing support for American politics.

\section{Additional lowrated goals:}

\#13: adding to family income;

\#14: providing household help;

\#15: adding childcare for own child;

\#16: establishing travel contact;

\#20: re-living a personal exchange experience;

\#25: practicing a foreign language;

\#29: learning about personal heritage;

\#30: sharing community hosting experience;

\#32: gaining community recognition;

\#43: aiding a less developed culture/society.

The above data suggests that these goals may have

less influence upon host family decisions for participating in intercultural exchange.

Summarizing the finding concerning the rating of importance of goals, both trained and untrained host 
TABLE I I

COMPARATIVE RATINGS OF MOST AND LEAST IMPORTANT GOALS BY TRAINED WITH UNTRAINED HOST FAMILIES

Goal

$\begin{array}{ll}\text { Trained Untrained } & * \\ \text { Mean SD Mean SD }\end{array}$

HIGH RATED GDALS (equal to or greater than 5):

2 Children interact with guest

3 Interact with specific guest

4 Share family's lifestyle

19 Develop guest personally

21 Have fun

23 Educate self

24 Understand another culture

36 Show American values/way of 1 ife

38 Practice religious principles

39 Experience intercul. exchange

$\begin{array}{lllll}4.96 & 1.56 & 5.57 & 1.29 & C A \\ 5.00 & 1.60 & 4.73 & 0.97 & C A \\ 5.83 & 0.89 & 5.60 & 0.77 & C A \\ 5.71 & 0.92 & 5.25 & 1.80 & \\ 5.00 & 1.25 & 5.35 & 1.34 & \\ 5.47 & 0.87 & 5.15 & 1.28 & C A \\ 5.67 & 0.96 & 5.40 & 1.21 & C A \\ 5.03 & 1.69 & 5.05 & 1.54 & C A \\ 6.17 & 0.87 & 4.08 & 2.54 & \\ 5.56 & 1.07 & 5.73 & 1.12 & C A\end{array}$

LOW RATED GOALS (equal to or less than 3):

$\begin{array}{lllll}2.17 & 1.13 & 1.33 & 0.59 & \text { IF } \\ 2.88 & 2.00 & 2.63 & 1.62 & \text { IF } \\ 2.83 & 1.86 & 4.00 & 2.83 & \text { IF } \\ 2.19 & 1.10 & 2.23 & 1.59 & \text { IF } \\ 2.07 & 1.54 & 1.96 & 1.85 & \text { IF } \\ 2.67 & 1.44 & 2.75 & 1.94 & \text { IF } \\ 0.93 & 0.26 & 0.96 & 0.14 & \\ 1.06 & 0.17 & 1.05 & 0.22 & \\ 1.00 & 0.35 & 1.00 & 0.00 & \\ 2.39 & 1.41 & 2.95 & 1.86 & \\ 1.64 & 1.21 & 3.44 & 2.85 & \\ 3.14 & 1.74 & 2.90 & 1.63 & \\ 3.17 & 1.26 & 2.68 & 1.94 & \text { CA } \\ 1.08 & 0.78 & 1.29 & 1.57 & \\ 3.64 & 1.77 & 2.90 & 1.73 & \\ 1.78 & 1.11 & 2.29 & 1.64 & \\ 2.67 & 1.36 & 2.45 & 1.69 & \text { CA } \\ 2.50 & 1.96 & 2.00 & 1.57 & \end{array}$

$\begin{array}{lllll}2.17 & 1.13 & 1.33 & 0.59 & \text { IF }\end{array}$

6 Strengthen marriage

8 Experience parenting boy or girl

9 Re-establish youth contact

10 Companionship for children

11 Please children

12 Positive role model for children

13 Add to family income

14 Provide household help

15 Add childcare for own child

16 Establish travel contact

20 Re-live exchange experience

25 Practice foreign language

28 Sensitize guest to cul. identity

29 Learn about heritage

30 Share community hosting

32 Gain community self-recognition

37 Develop support for politics

43 Aid less developed society 
families rank Cultural Awareness goals significantly more important than Intra-family Needs goals.

\section{ACCOMPLISHMENT OF GOALS}

\section{Rㅡㅗ느ㄴㅗㅗ}

This facet of the study examines interculturally trained and untrained host families" perceived level of goal accomplishment.

2. Do host families who receive intercultural training report the level of accomplishment of their goals differently than host families who do not receive intercultural training?

Table III displays the means, standard deviations and significance levels of difference for the trained and untrained host families' ratings evaluating the level of accomplishment of the 43 goals on the questionnaire. One goal "To put your religious principles into practice" (\#38) tested significant $(p=.000)$. This statistical effect may be a result of recruiting host families from church communities for one of the programs. Qverall, the results strongly show that trained host families do not report their level of goal accomplishment differently than host families who have not received intercultural training. 2a. Do host families who receive intercultural training report the level of accomplishment of goals 
TABLE III

MEAN RATINGS OF GOAL ACCOMPLISHMENT

BY TRAINED AND UNTRAINED GROUPS

Goal

1 Establish long-term relationship 4.831 .46

2 Children interact with guest

3 Interact with other cultures

4 Share family's lifestyle

5 Bring family closer

6 Strengthen marriage

7 Experience parenting

8 Experience parenting boy or girl

9 Re-establish child/youth care

10 Companionship for children

11 Please children

12 Positive role model for children

13 Add to family income

14 Provide household help

15 Add childcare for own child

16 Establish travel contact

17 Develop personally

18 Develop family personally

19 Develop guest personally

$20 \mathrm{Re}-\mathrm{live}$ exchange experience

21 Have fun

22 Satisfy hosting curiosity

23 Educate self

24 Understand another culture

25 Practice foreign language

26 Help guest learn English

27 Aid guest's ed. development

28 Sensitize guest to cul. identity

29 Learn about heritage

30 Share community hosting

31 Help program coordinator

32 Gain community self-recognition

33 Risk unpredictable challenge

34 Change family views of cultures

35 Get guest's percept' $n$ of America

36 Show American values/way of life

37 Develop support for politics

38 Practice religious principles

39 Experience intercul. exchange

40 Get knowledge for human welfare

41 Guest's knowledge-human welfare

42 Promote intern'l goodwill/peace

43 Aid a less developed society
Trained
Mean $5 D$
$N=18$

$\begin{array}{ll}4.83 & 1.46 \\ 4.83 & 1.80\end{array}$

4.721 .48

$5.58 \quad 0.96$

4.001 .65

2.931 .67

$3.42 \quad 2.85$

3.312 .28

4.702 .02

$\begin{array}{lll}3.88 & 1.48\end{array}$

2.632 .08

$3.50 \quad 2.48$

1.230 .90

$2.18 \quad 1.44$

$\begin{array}{lll}1.56 & 0.90\end{array}$

3.141 .48

4.671 .40

4.481 .65

5.121 .15

2.411 .83

5.331 .64

4.182 .06

$5.50 \quad 0.96$

5.221 .27

2.751 .50

4.171 .28

4.421 .87

$3.28 \quad 1.29$

1.211 .05

3.811 .80

5.211 .72

2.311 .24

4.251 .77

4.031 .62

$4.78 \quad 1.31$

4.831 .40

2.611 .46

$5.58 \quad 1.02$

5.471 .06

4.531 .29

4.191 .36

$4.56 \quad 1.53$

2.301 .76
Untrained Sig. Mean SD Level $N=20$

$4.30 \quad 1.54 \quad .282$

$4.93 \quad 1.70 \quad .884$

$4.73 \quad 1.39 .995$

5.631 .31 .912

$\begin{array}{llll}3.92 & 1.48 & .883\end{array}$

$1.630 .94 \quad .015$

$4.42 \quad 1.93 \quad .494$

$3.19 \quad 1.93 \quad .907$

$5.25 \quad 2.87 \quad .745$

$\begin{array}{llll}3.58 & 2.24 & .743\end{array}$

2.12 1.61 .586

$\begin{array}{llll}3.75 & 1.78 & .781\end{array}$

0.910 .20 .162

$1.531 .34 \quad .163$

$\begin{array}{llll}1.23 & 0.70 & .355\end{array}$

$\begin{array}{llll}3.63 & 1.84 & .380\end{array}$

$\begin{array}{llll}4.38 & 1.91 & .598\end{array}$

$\begin{array}{llll}3.87 & 1.91 & .358\end{array}$

$\begin{array}{llll}4.88 & 1.62 & .609\end{array}$

$3.19 \quad 2.62 .454$

$5.53 \quad 1.63 \quad .720$

$4.35 \quad 2.42 .817$

5.331 .43 .663

$4.78 \quad 1.19 .270$

$2.78 \quad 1.56 \quad .960$

$3.90 \quad 1.77 \quad .602$

$4.35 \quad 1.92 .915$

$2.92 \quad 2.14 .546$

$\begin{array}{llll}0.79 & 0.25 & .121\end{array}$

$\begin{array}{llll}3.48 & 1.82 & .578\end{array}$

$\begin{array}{llll}4.37 & 2.44 & .247\end{array}$

$2.61 \quad 1.66 \quad .540$

$\begin{array}{llll}4.40 & 1.88 & .802\end{array}$

$\begin{array}{llll}3.68 & 2.18 & .583\end{array}$

$3.651 .73 \quad .031$

$\begin{array}{llll}4.73 & 1.31 & .807\end{array}$

2. $15 \quad 1.43 \quad .333$

3.432 .17 .000

$5.38 \quad 1.54 \quad .824$

$4.00 \quad 2.03 \quad .351$

$\begin{array}{llll}3.88 & 1.86 & .553\end{array}$

$\begin{array}{llll}4.33 & 1.88 & .684\end{array}$

$2.08 \quad 1.64 \quad .708$ 
regarding the development of cultural awareness differently than families who do not receive intercultural training? The questionnaire included host family goals which emphasized cultural awareness. These denoted cultural difference as a dynamic component of the goal. Looking specifically at these goals that emphasize Cultural Awareness (noted in Chapter II) there is no difference reported between trained and untrained host families of their level of accomplishment.

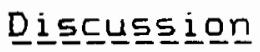

Caution is appropriate during this phase of interpretation due to the tendency of the subjects to report a lower level of accomplishment for goals they rated as less important and higher accomplishment for all goals rated more important. This may be an accurate reflection of participants' feelings, but might also be an artifact of the instrument design (see "Limitations of Study" in Chapter Four).

Although there is no significant difference in the reporting of the level of goal accomplishment between trained and untrained host family groups, there is a strong commonality in both trained and untrained groups in reporting a higher level of accomplishment of Cultural Awareness goals and a lower level of accomplishment of Intra-family goals. T-testing reports a significant difference $(p=.000)$ between Cultural Awareness and 
Intra-family goal accomplishment. The following discussion explains the data which supports this finding.

Examination of the data shows that 9 of the 43 goals were perceived by both groups to have a mean of nearly 5 or above on the seven point scale in the questionnaire (see Table IV). Looking at these goals which are rated as highly accomplished, there is a tendency by both groups of host families towards rating Cultural Awareness goals at a higher level of accomplishment. Four of the nine goals which report a high level of accomplishment emphasize cultural awareness; one of the nine goals addresses intra-family needs. The nine goals reported at a higher level of accomplishment are listed below. The first four goals represent the cultural awareness category.

High level of accomplishment-Cultural Awareness goals: \#4: sharing the family's lifestyle; \#23: having an educational experience by hosting; \#24: achieving understanding of another culture; \#39: having a personal intercultural experience.

High level of accomplishment-Intra-fanily Needs goals: \#9: re-establishing youth contact.

\section{High level of accomplishment--additional goals:}

\#19: furthering the guest's personal development;

\#21: having fun;

\#31: helping program coordinator;

\#38: putting religious principles into practice. 
Overall, these goals may suggest what goals are perceived by host families to be accomplished by participating in an exchange program. It is interesting to note that Lowe, Askling, and Bates (1984) suggest that one of four impacts of intercultural exchange is increased interest and understanding of cultural difference. Goals which address cultural awareness would seem to support such an impact.

Two of the goals rated as low in accomplishment 3 or less by either group on the anchored seven-interval scale) are classified as intra-family and two are classified as emphasizing cultural awareness (see Table IV). It is important to note that Goal \#37, "To develop friends and supporters for the American way of life by giving persons from other countries a better understanding of our political system", though marked as dependent upon cultural difference, could have been rated as having a lower level of accomplishment because it was interpreted to counter cultural awareness. If so, its rating emphasizes the higher reporting of accomplishing goals which consider cultural awareness. The 12 goals which are reported at a lower level of accomplishment include:

\section{Low level of accoaplishment-Intra-fanily Needs goals:}

\#6: strengthening the host marriage;

\#1: pleasing children. 
Low level of accomplishment-Cultural Awareness goals:

\#2B: sensitizing guest to cultural identity;

\#37: developing support for American politics.

\section{Low level of accomplishnent-additional goals:}

\#13: adding to family income;

\#14: providing household help;

\#15: providing childcare for own children;

\#20: re-living a personal exchange experience;

\#25: practicing foreign language;

\#29: learning about personal heritage;

\#32: gaining community self-recognition;

\#43: aiding a less developed culture/society.

The above data may suggest what goals are not perceived by host families to be accomplished. Table IV displays the ratings of goal accomplishment by trained and untrained hosts.

Summarizing, both trained and untrained host families strongly report a higher level of accomplishment for goals which emphasize Cultural Awareness compared to goals which address Intra-family Needs.

ASSOCIATION OF GOALS AND INTERCULTURAL TRAINING

R토느느ㄴㅗㅡ

The final phase of data analysis explored if there was an association between host family goals and intercultural training. The design looked at the goals 
within each of the trained and untrained host family groups and evaluated to what extent the data showed a relationship between the importance of goals and the reported level of accomplishment of the goals. This procedure was implemented

\section{TABLE IV}

\section{COMPARATIVE RATINGS OF MOST AND LEAST ACCOMPLISHED GOALS BY TRAINED WITH UNTRAINED}

Goal

Trained Untrained
Mean SD Mean SD

HIGH RATED GOALS (equal to or greater than 5):

$\begin{array}{llllll}4 \text { Share family's lifestyle } & 5.58 & 0.96 & 5.63 & 1.31 & \text { CA } \\ 9 \text { Re-establish child/youth care } & 4.70 & 2.02 & 5.25 & 2.87 & \text { IF } \\ 19 \text { Develop guest personally } & 5.12 & 1.15 & 4.88 & 1.62 & \\ 21 \text { Have fun } & 5.331 .64 & 5.53 & 1.63 & \\ \text { 23 Educate self } & 5.50 & 0.96 & 5.33 & 1.43 & \text { CA } \\ 24 \text { Understand another culture } & 5.22 & 1.27 & 4.78 & 1.19 & \text { CA } \\ 31 \text { Help program coordinator } & 5.21 & 1.72 & 4.37 & 2.44 & \\ 38 \text { Practice religious principles } & 5.58 & 1.02 & 3.43 & 2.17 & \\ 39 \text { Experience intercul. exchange } & 5.47 & 1.06 & 5.38 & 1.54 & \text { CA }\end{array}$
LOW RATED GOALS (equal to or less than 3 ):

$\begin{array}{lllllll}6 & \text { Strengthen marriage } & 2.93 & 1.67 & 1.63 & 0.94 & \text { IF } \\ 11 \text { Please children } & 2.63 & 2.08 & 2.12 & 1.61 & \text { IF } \\ 13 \text { Add to family income } & 1.23 & 0.90 & 0.91 & 0.20 & \\ 14 \text { Provide household help } & 2.18 & 1.44 & 1.53 & 1.34 & \\ 15 \text { Add childcare for own child } & 1.56 & 0.90 & 1.23 & 0.70 & \\ 20 \text { Re-live exchange experience } & 2.41 & 1.83 & 3.19 & 2.62 \\ 25 \text { Practice foreign language } & 2.75 & 1.50 & 2.78 & 1.56 & \\ 28 \text { Sensitize guest to cul. identity } & 3.28 & 1.29 & 2.92 & 2.14 & \text { CA } \\ 29 \text { Learn about heritage } & 1.21 & 1.05 & 0.79 & 0.25 & \\ 32 \text { Gain community self-recognition } & 2.31 & 1.24 & 2.61 & 1.66 & \\ 37 \text { Develop support for politics } & 2.61 & 1.46 & 2.15 & 1.43 & \text { CA } \\ 43 \text { Aid a less developed society } & 2.30 & 1.76 & 2.08 & 1.64 & \end{array}$

* IF: Intra-family acts as a generic term which groups goals that address strengthening the family relationship regardless of the fact that the guest is an intercultural representative.

*CA: Cultural awareness denotes cultural difference as a dynamic component of the goal. 
to examine if trained host families would report a relationship between importance and accomplishment of goals differently from untrained host families. In other words, it explored to what extent intercultural training could be associated with a relationship between goal importance and accomplishment.

A second analysis looked specifically at the goals which were rated as most important by the trained and untrained host families to examine if the correlation between importance and accomplishment differed between the trained and untrained families for these important goals.

3 \& 3a: To what extent is there a relationship between trained host family ratings of importance and ratings of accomplishment of goals? To what extent is there a relationship between untrained host family ratings of importance and ratings of accomplishment of goals?

The relationship between importance and accomplishment of the goals within each of the trained and untrained groups is presented in Table $\mathrm{V}$. The Pearson Product-Moment Correlation between importance and accomplishment for the trained host families was $+.6043(N=18, P<.004)$ and the untrained host families was $+.7176(N=20, P(.000)$. The moderately high correlation for trained host families suggests there is a substantial relationship between goal importance and accomplishment and 
the untrained host families" high correlation suggests there is a marked relationship between goal importance and accomplishment (Guilford, 1956, P. 145). The results show that untrained host families report a stronger relationship between the rating of goal importance and the reported level of accomplishment than interculturally trained host families.

\section{TABLE $V$}

PEARSON CORRELATION COEFFICIENTS BETWEEN IMPORTANCE AND ACCOMPLISHMENT OF 43 HOSTING GOALS FOR TRAINED AND UNTRAINED HOST FAMILIES

$\begin{array}{lcc} & \text { Trained } & \text { Untrained } \\ \text { Pearson r (Importance/Accomplishment) } & +.6043 & +.7176 \\ \text { Probability } & .004 & .000 \\ N & 18 & 20\end{array}$

Table VI displays the Pearson Product-Moment

Correlation coefficients between goal importance and accomplishment specifically for the goals trained and untrained host families rated as highly important (either group rated the goals to have a mean of nearly 5 or above on an anchored seven-interval scale on the questionnaire). The Pearson Product-Moment Correlation between importance and accomplishment for the trained host families was +.5926 $(N=18, P<.005)$ and for the untrained host families was $+.6367(N=20, P<.001)$. Both groups show a moderate correlation which suggests there is a substantial relationship in both trained and untrained host family groups between the goals that are rated highly in importance 
and their reported level of accomplishment. The results do not support an association between intercultural training and higher goal accomplishment for goals that are rated highly important for either for the goals as a whole nor those rated highly important.

\section{TABLE VI}

PEARSON CORRELATION COEFFICIENTS BETWEEN IMPORTANCE AND ACCOMPLISHMENT OF THE MOST IMPORTANT HOSTING GOALS FOR TRAINED AND UNTRAINED HOST FAMILIES

$\begin{array}{lcc} & \text { Trained } & \text { Untrained } \\ \text { Pearson } r(\text { Importance/Accomplishment }) & +.5926 & +.6367 \\ \text { Probability } & .005 & .001 \\ N & 18 & 20\end{array}$

\section{Diㅗ드ㄴㅡㅗㅡㅗ프므}

Although goal accomplishment and importance are significantly correlated in both trained and untrained groups, the correlation is lower for trained host families thar for untrained ones. Assuming the difference in significant correlation is meaningful, it could be explained as follows.

If intercultural training developed a high degree of intercultural awareness and respect for the complexity and diversity of culture and cultural values, trained host families may have evaluated goals as unattainable regardless of the rating of goal importance. The development of intercultural awareness is congruent with the overall training goals of intercultural training as stated by 
Clarke (1971),"...awareness of cultural differences in terms of values, customs, and behaviors which affect human relations" (cited in Pedersen and Hoopes, 1975, p. 90). And, perhaps families entered into the experience with Hanvey's (1979) assumption that contact does not automatically lead to understanding but that "There must be readiness to respect and accept, a capacity to participate. That participation must be reinforced by rewards that matter to the participant" (p. 51). If the trained host families realized that effective intercultural interaction requires a capacity to acknowledge cultural difference in all aspects of human relations, then their reporting of rewarding accomplishment may have been dependent upon attaining sophisticated patterns of interaction regardless of the level of goal importance.

It is interesting to note that both groups of host families similarly report a substantial association between importance and accomplishment of the ten most important goals (see Table VI). Even though goals are rated to be important, the association between goal importance and the reported level of accomplishment for interculturally trained host families does not differ from the association reported by untrained families. Apparently, if goals are highly rated in importance, host families in general tend to report a similar level of accomplishment. The results do not support an association between intercultural 
training and higher goal accomplishment for goals rated highly important.

\section{SUMMARY}

This chapter has presented and discussed the results of the study which investigated the importance and accomplishment of host family goals and explored if goals and intercultural training are interrelated.

The first phase of the data analysis (frequency testing) examined which goals were rated as important. Ten goals held a higher degree of importance for the two groups and 18 goals were rated of less importance. Similarly, the data were analyzed to determine which goals were perceived to have been accomplished. Nine goals were rated of higher accomplishment and 12 goals were rated of lower accomplishment.

The second phase of the data analysis (t-tests) checked the degree of difference between trained and untrained perceptions of importance and accomplishment. Results established that there was virtually no significant statistical difference between the importance of goals of the two groups, nor was there a significant statistical difference between the level of accomplishment of goals of the two groups. Neither intra-family or cultural awareness goals showed difference within the two groups but both groups 
reported that goals which emphasized cultural awareness were rated overall to be more important.

The third phase of data analyis (Pearson Product-

Moment Correlation) assessed association of importance and accomplishment within each of the trained and untrained host family groups. Untrained host families show a stronger relationship between goal importance and the reported level of goal accomplishment. Looking specifically at the goals which both groups rated to have high importance, both groups reported a substantial association between goal importance and the level of goal accomplishment. 
CHAPTER IV

CONCLUSION, LIMITATIONS, AND DIRECTIONS FOR FUTURE RESEARCH

This final chapter includes implications of the study as a whole for host family programs and intercultural training for host family programs, limitations of the study, and directions for future research.

IMPLICATIONS FOR HOST FAMILY PROGRAMS

To the best of the author's knowledge this is one of the first studies (along with Fisher-Moore's research) which investigates goals of host families from the host's perspective, not the agency's perspective. Ten goals were reported by host families to have a high degree of importance:

- having children interact with a representative of another culture;

- interacting with a representative of a specific culture;

- sharing the family's lifestyle;

- furthering the guest's personal development;

- having fun;

- having an educational experience by hosting;

- achieving understanding of another culture;

- showing American values and way of life; 
- putting religious principles into practice;

- having a personal intercultural experience

(see Chapter IV: Future Research for comparison of FisherMoore data regarding goals perceived to be important by rural host families).

Host family program directors may use this information as a guide to recruit host families. No longer must intercultural exchange be dependent upon attempting to align host family reasons with documented organizational

objectives to encourage participation. Goals perceived by host families to hold importance have been identified. Furthermore, the study distinguished which of the goals emphasized cultural awareness to be the influencing factor for participation in contrast to intra-family needs goals. This offers a selective recruiting factor if predetermined by the program that a cultural awareness emphasis embraces quality host families.

The emphasis upon cultural awareness is also supported by Lowe, Askling, and Bates (1984) who report that an increased interest in and understanding of cultural difference are dimensions of impact of international exchange. Knowing that international contact encourages exploration of cultural difference and that host families ascribe importance to goals concerning cultural awareness, host family programs may now promote the hosting experience as meeting this host family desire. 
IMPLICATIONS FOR INTERCULTURAL TRAINING OF HOST FAMILIES

Results of the study did not support that training host families correlates with a higher level of goal accomplishment or a statistically significant difference in the importance of goals than for untrained host families. The study suggests that 1 ) it may be inappropriate to market intercultural training to host families or exchange programs upon the premise that host family satisfaction will be increased. 2) Nor should it be assumed that host families' goals can easily be molded by a brief period of training. Improving host families' goal satisfaction or influencing goal expectations does not appear to offer a training format objective.

Bennett (1985) and Triandis (1977) advocate that the participants" goals of an exchange program as well as the organization's goals should be considered by the intercultural trainer when developing training. The results of this study begin to identify goals for participation. While incorporating the training content and objectives that intercultural literature prescribe, trainers may want to look at host family goals. Bennett (1985) states,

Even if a trainer can only minimally assess these goals informally at the beginning of a brief program, recognition of the audience's needs is a minimal prerequisite to a successful multidimensional training program. ( $P .204$ )

The research design deliberately did not pre-assess host family goals to prevent aligning the training content 
to emphasize particular goals which may have distorted the data.

This subject will be further addressed in suggestions for future research when the discussion concerning intercultural training extends beyond goal importance and accomplishment.

\section{LIMITATIONS DF THE STUDY}

Typical to research, this investigation displayed certain limitations in regard to the research design, the evaluation process, and the testing instrument.

In regard to the research design, it would have enhanced statistical clean entrance if the two host family groups had not been pre-selected and recruited by separate program directors. This brings into question the sample selection. A pre- and post-test questionnaire could have established commonality between the two groups to check for an influential recruitment effect.

Neither did the study investigate if intercultural training changes goals. A pre-test of both the trained and untrained groups to establish goals prior to training would have been instructive. Similarly, a test was not conducted before the hosting experience itself to establish the pre-experience hosting goals. A third factor to be taken into consideration is that the families may have already had their goals in mind before they were invited to the training. 
Training families and then randomly selecting from the families to host and participate in the research may have resulted in different responses to the instrument.

The research design did not account for the families who chose not to participate. Complete anonymity and voluntary participation prevented conducting follow-up to inquire if discouraged or dissatisfied families completed the questionnaire. Goal identification and satisfaction may have been reported and rated according to a positive experience. All but two of the families who participated in the research stated that they would readily host in the future.

The issue of randomization can be discussed by examining the ethical implications of not training a group of the host families. Triandis (1977) suggests that there are situations when randomization is not possible. This particular study was initiated after host families had been recruited for one of the programs, eliminating the possibility of requiring training.

Another factor regarding sample reliability lies in sample size. Cohen (1977) states,

Moreover and most important whatever else sample reliability may be dependent upon, it always depends upon the size of the sample... as is intuitively obvious, increases in sample size increase statistical power, the probability of detecting the phenomenon under test. ( $p .7$ )

It could be argued that the sample sizes of 18 and 20 were not large enough for difference to be detected by t-testing. 
Minimal trends may have existed between the two groups but were not statistically identifiable due to small sample size.

The small sample size may also have influenced the Pearson Product-Moment Correlation results. Tucker, Weaver, and Berryman-Fink (1981) suggest that correlation studies have one major shortcoming--the sample size is too small. Suggesting that "it is a matter of empirical fact, a large amount of error tends to occur ... a minimum of two hundred subjects should be included" (p. 193). To validate the high degree of correlation between goal importance and accomplishment for both trained and untrained groups, the study should be replicated using a much larger sample size.

Another factor which may have increased the problem of small sample size was the decision to collapse spouses together as a family unit. The advantage of this procedure was to really deal with families, not individuals. But the disadvantage was that different spouse's reactions were lost; collapsed averages may have masked some significant correlations, and the sample size was reduced.

Reviewing the evaluation process, the second issue of limitations, suggests that the total involvement of the researcher as program coordinator, trainer and evaluator challenges optimal research. Perhaps this explains why 
one of the most accomplished goals perceived by the trained host family group was "helping the program coordinator".

Bennett (1985) suggests that training pushes beyond orientation and entertains a skills approach which addresses behavioral goals. However, such behavioral goals were not evaluated in this study which included intercultural training. The process of identifying and evaluating host family goals was dependent upon a questionnaire which did not emphasize measurable behavior. Nor did pre-determined training goals interplay within the design to directly influence particular behavior. Lacking the behavioral component limited the scope of the evaluation of this research (see "Directions for Future Research" in this chapter).

The third issue among limitations addresses the testing instrument, the Fisher-Moore Host Family Goals Questionnaire. Reviewing the instrument, the researcher raises two questions of design. First, the instrument structured certain questions utilizing the five goals identifying the general nature of the sponsoring organizations over the last forty years as assessed by the Committee on Education Interchange Policy of the Institute of International Education. Part of the original wording was used which represents language structure common to their respective decade. As one subject commented, "I found some of the questions in this questionnaire difficult 
to understand. I wasn't sure if I was interpreting them correctly."

Secondly, particular questions on the questionnaire which addressed the issue of cultural awareness might have been interpreted differently by the subjects. If subjects interpreted particular questions which addressed cultural awareness to advocate goals that did not acknowledge and validate cultural difference, they may have rated them as having lower importance. For instance, the question "To develop friends and supporters for the American way of life by giving persons from other cultures a better understanding of our political system" might have been seen as ethnocentric rather than supportive of cultural awareness.

The order of the importance and accomplishment components of each question also merits investigation. Would different results have occurred if the accomplishment issue had been asked prior to the importance? As Chapter III reports, a general trend for rating the level of accomplishment lower to correspond to the lower perceived importance rating brings into question what antecedents cause people to respond. Two subjects commented:

... I wasn't sure if I was interpreting them correctly and had some problems with the 'accomplishment' part.

I found the questionnaire a little vague when I needed to respond to a question which indicated a goal I hadn't considered... had a problem answering Part B (accomplishment) of those questions. 


\section{DIRECTIONS FOR FUTURE RESEARCH}

Several implications for future research can be derived from this research.

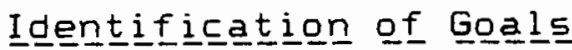

Reviewing the procedures raises the question: What is the most strategic research design which effectively identifies goals and measures accomplishment? The preceding discussion which identifies limitations suggests that a pre-training and pre-hosting goal questionnaire could be given to explore if an impact of intercultural training and/or an impact of the hosting experience itself influences goals.

$$
\text { A second factor to consider in the future concerns a }
$$
review of the theoretical basis of research. Hawes (1977) suggests that communication research is hampered when theory construction precedes extensive description and interpretation. Phenomena must first be identified and then it can be determined how they came into being and are maintained. Perhaps host family goals first need to be identified, then to be interpreted on how they developed a status of importance, and then to be researched to the causal relationship.

This study has initiated goal identification of host families. Similarly, Fisher-Moore's (1989) data reveals that certain host family goals coincide with the present 
study. Table VII contrasts the means of the most important goals as distinguished by the Fisher-Moore Host Family Goals Questionnaire (see Appendix A). The results of the current study are labeled as "Urban Trained and Urban Not Trained"; the results of the Fisher-Moore study are labeled as "Rural Not Trained".

Data suggests that nine of the ten most important goals for both the urban (trained and untrained) and rural groups coincided. Both groups rated these goals as being the most important among the 43 goals listed on the questionnaire. They include:

\#2: having children interact with a representative of another culture;

\#3: interacting with a representative of a specific culture;

\#4: sharing the family's lifestyle;

\#19: furthering the guest's personal development;

\#21: having fun;

\#23: having an educational experience by hosting;

\#24: achieving understanding of another culture;

\#36: showing American values and way of 1 ife;

\#39: having a personal intercultural experience.

Each study separately distinguished one goal as having importance. Goal \#38: "To put your religious principles into practice" may be the biased result of recruiting host families from church communities for the "Urban Trained". Goal \#42: "To promote international understanding and 
goodwill among the peoples of the world as a contribution to peace" appears to be perceived as more important only to the rural host family. Further research should examine the recruiting procedures and brochures to determine what themes were promoted within that program.

Further comparative research could address the issue: To what extent does a population of host families in an urban area appear similar to rural host families?

Demographic analysis would clarify the definition of host family.

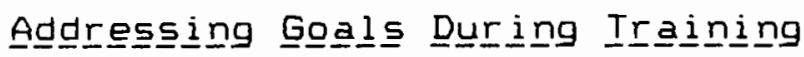

Now that there is a basis which identifies hosting goals, research could pursue if there is a difference in goal accomplishment if the intercultural training purposefully addressed or verbalized specific hosting goals, not just intercultural awareness. Should the trainer propose to raise people's consciousness of hosting goals which correspond to training goals and intercultural exchange impact? The current research may have measured hosting issues that the training did not address. (By design, pre-conceived hosting goals were not integrated into the training format.)

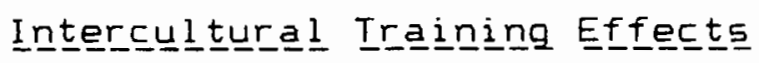

Expanding beyond goal identification and acccomplishment, future research may seek to identify other 
MEAN RATINGS OF MOST IMPORTANT GOALS CONTRASTED AMONG URBAN AND RURAL HOST FAMILY GROUPS

GOAL

$\begin{array}{ccc}\text { URBAN* } & \begin{array}{c}\text { URBAN** } \\ \text { NRAT }\end{array} & \begin{array}{c}\text { RURAL*** } \\ \text { NOT }\end{array} \\ \text { TRAINED } & \text { TRAINED } \\ \text { Mean } & \text { Mean } & \text { Mean }\end{array}$

2 Children interact with guest

3 Interact with specifc culture

4 Share family's lifestyle

19 Develop guest personally

21 Have fun

23 Educate self

24 Understand another culture

36 Show American values/way of 1 ife

38 Practice religious principles

39 Experience intercul. exchange

42 Promote intern'l goodwill/peace

4.96
5.00
5.83
5.71
5.00
5.47
5.67
5.03
6.17
5.56
4.75

5.57

4.73

5.60

5.25

5.35

5.15

5.40

5.05

4.08

5.73

4.38

6.13

5.11

5.51

5.35

5.70

5.13

5.34

5.52

3.78

5.00

5.08

\section{MEAN RATINGS OF MOST ACCOMPLISHED GOALS CONTRASTED} AMONG URBAN AND RURAL HOST FAMILY GROUPS

GDAL

\author{
URBAN* \\ TRAINED
}

Mean

4.83

4.72

5.58

5.12

5.33

4.18

5.50

5.22

5.21

31 Help program coordinator

36 Show American values/way of 1 ife

38 Practice religious principles

39 Experience intercul. exchange

42 Promote intern'l goodwill/peace
4.83

5.58

5.47

4.56

URBAN** RURAL***
NOT NOT
TRAINED TRAINED

Mean

Mean

4.93

5.84

4.73

5.03

5.63

5.56

4.88

5.32

5.53

5.73

4.35

5.00

5.33

5.34

4.78

5.55

4.37

4.35

4.73

5.46

3.43

3.54

5.38

5.00

4.33

* Urban Trained: Church oriented host families.

* Urban Not Trained: Church and non-church host families.

* * Rural Not Trained: Non-church host families. 
effects of intercultural training. Triandis (1977) suggests that evaluation procedures are too restricted in scope, obtaining measurements on only a few dependent variables. While looking at major effects, research may miss the smaller or unusual effects. Other questions should be considered. Do students perceive the experience differently depending upon whether their host family was trained? Was it a more pleasant and satisfying experience for the student? This design would require the student to also respond to a questionnaire. Exchange goals and the levels of accomplishment could be contrasted and compared between hosts and hostees. Maintaining that the host and intercultural guest experience is not mutually exclusive, Triandis (1977) implicates intercultural training with formative evaluation. One-shot basis evaluation of effectiveness needs to extend to include feedback from both intercultural parties.

Other exploratory issues suggest further inquiry which focus upon the host family. Do interculturally trained hosts more readily engage in repeated hosting opportunities? Do they demonstrate differently from untrained hosts the traits or impact of intercultural exchange alumni as expressed in literature? The four dimensions of impact presented by Lowe, Askling, and Bates (1984) that could be researched include increased interest and understanding in cultural differences, forming of intimate relationships, 
increased concern about world issues, and host participation in national foreign affairs.

Hammer (1984) demonstrates an effective usage of the behavioral observation methodology developed by Ruben (1976) to explore the effects of intercultural training. Supporting Bennett's (1985) suppostion that training involves skills, further research could utilize behaviorally based indices of training and hosting goals to measure levels of goal accompli shment. 


\section{REFERENCES CITED}

Amir, Y. \& Garti, C. (1977). Situational and personal influence on attitude change following ethnic contact.

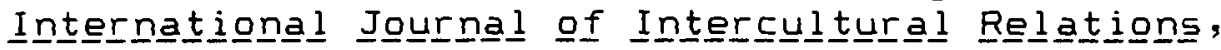
1 , 58-75.

Barna, L. M. (1985). Stumbling blocks in intercultural communication. In L. A. Samovar \& R. E. Porter (Eds.),

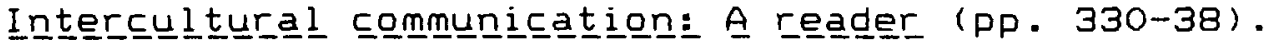
Belmont, CA: Wadsworth Publishing.

Batchelder, D. (1978). Training U.S. students going abroad. In D. S. Hoopes, P. B. Pedersen \& G. W. Renwick (Eds.),

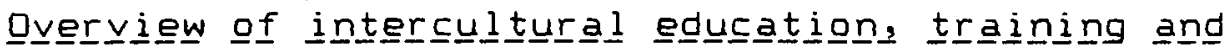

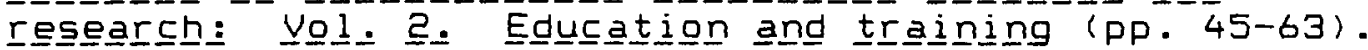
Washington D.C.: Society of Education, Training, and Research.

Bennett, J.M. (1986). Modes of cross-cultural training: Conceptualizing cross-cultural training as education.

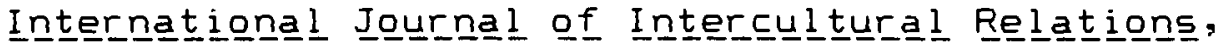
10 , $117-134$.

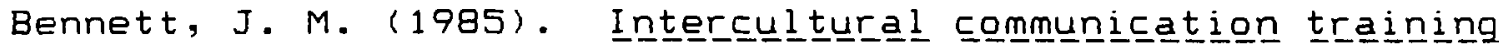

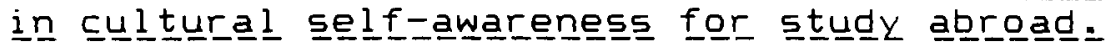
Unpublished doctoral dissertation, University of Michigan, Michigan.

Bochner, 5. (1982). The social psychology of cross-cultural

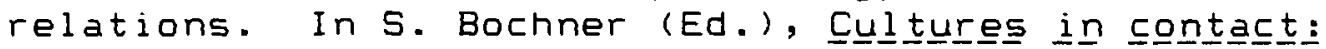

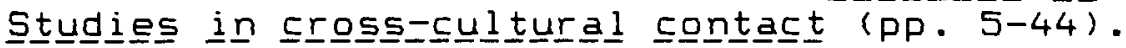
oxford: Pergamon Press.

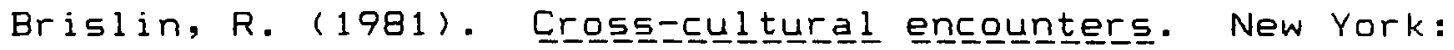
Pergamon Press.

Brislin, R., Landis, D. \& Brandt, M. E. (1983). Conceptualization of intercultural behavior and training. In D. Landis \& R. Brislin (Eds.), ㅂaㅁdㅁoㅁ․

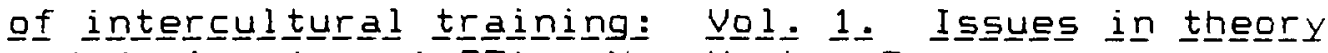
and des $\underline{i} g \underline{\text { n }}$ (PP. 1-35). New York: Pergamon. 
Clarke, C. H. \& Hoopes, D. S. (1975). Goals and leadership in intercultural communication workshops. In

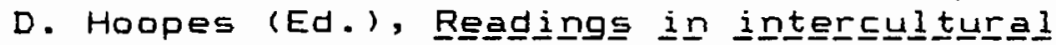

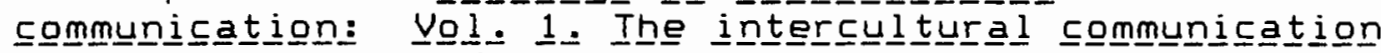
workshog (PP. 6o-72). Pittsburgh: The Intercultural Communications Network.

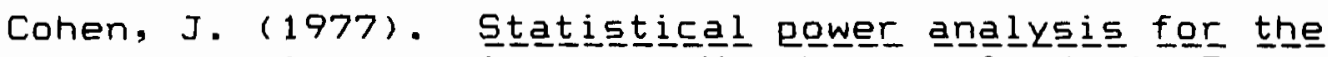

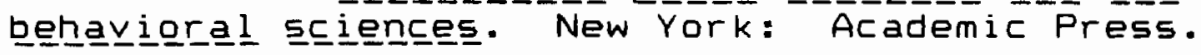

Fisher-Moore, D. (1989). Goals of international exchange: An exploratory study of why American host families participate in international exchange programs. Unpublished thesis. Portland State University, Speech Communication Department, Portland, DR.

Grove, C. (1982). Improving intercultural learning through orientation of 50 journers. Occasional Papers in Intercultural Learning 1. New York: AFS International/Intercultural Programs, Inc.

Grove, C. (1984, September). Dynamics of international host families. Paper presented at the First National Conference of the Transcultural Family, Columbus, $\mathrm{OH}$.

Grove, C. \& Hansel, B. (1987). AFS orientation handbook, 6. New York: AFS International/Intercultural Programs, Inc..

Guilford, J. P. (1956). Fundamental statㅗㅡ느도 프

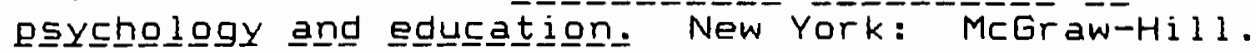

Hammer, M. R. (1984). The effects of an intercultural communication workshop on participants" intercultural communication competence: An exploratory study.

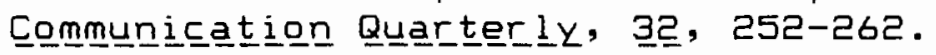

Hanvey, R. G. (1979). Cross-cultural awareness. In E. C. Smith \& L. F. Luce (Eds.), Ioward internationnali ism:

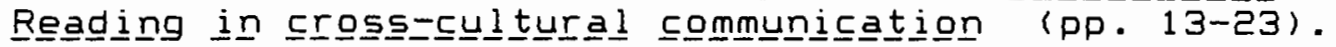
Rowley, MA: Newberry House Publishers.

Hawes, F. \& Kealey, D. J. (1981). An empirical study of Canadian technical assistance: Adaptation and

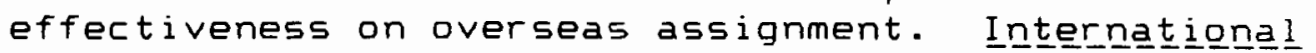

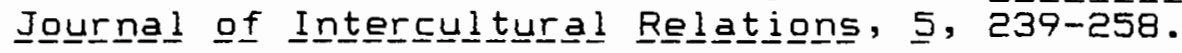


Hoopes, D. S. (1975). Alternative designs and uses: What is an intercultural communication workshop? In D. Hoopes

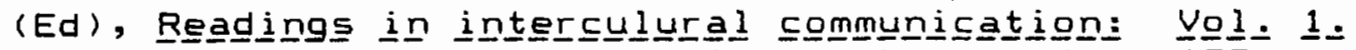

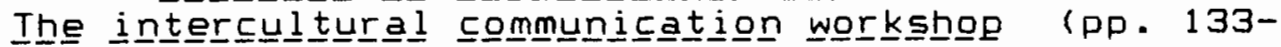
137). Pittsburgh: The Intercultural Communications Network.

Kelman, H. C. (1962). Changing attitudes through

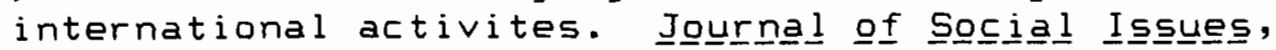
$\underline{1}$, $68-87$.

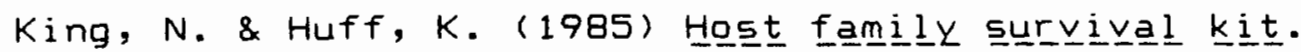
Yarmouth, Maine: Intercultural Press.

Kohls, L. R. (1987). Four traditional approaches to developing cross-cultural preparedness in adults: Education, training, orientation, and briefing.

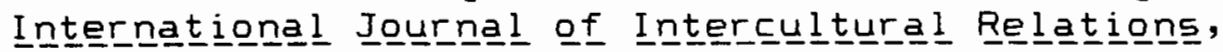
$1 \underline{1}, 89-105$.

Lowe, G., Askling, L.R. \& Bates, A. (1984). The Impact of intercultural contact on host families. Internnationonal

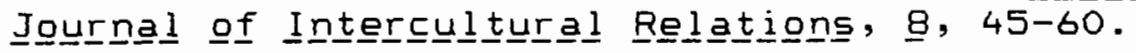

Mestenhauser, J. A. (1983), Learning from sojourners and how they impact the environment. In D. Landis and

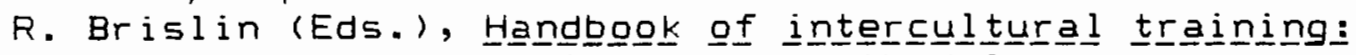
ㅂol. 르. Issuㅡㄴㅗ in training and methodoglogy (PP. 153-185). New York: Pergamon.

Martin, J. N. (1986). Training issues in cross-cultural

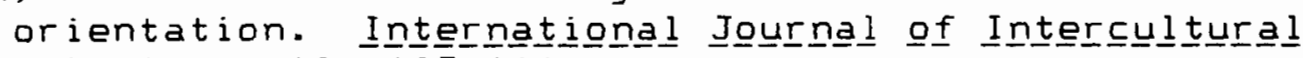
Relations, 10 , $103-116$.

Moran, R. (1975). Intercultural communication workshop at the University of Minnesota. In D. Hoopes (Ed.),

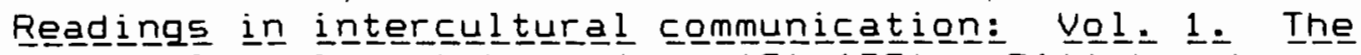

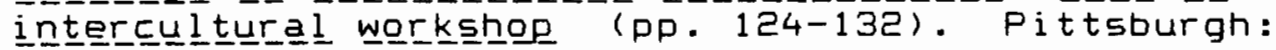
The Intercultural Communications Network.

Paige, R. M. (1983). Cultures in contact: On intercultural relations among American and foreign students in the United States university context. In D. Landis \& R. M.

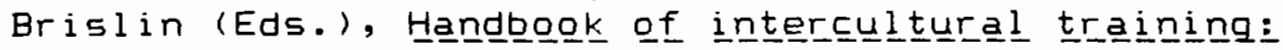

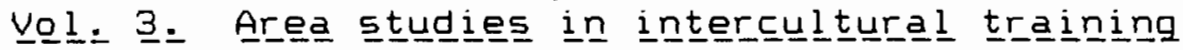
(pp. 102-129). New York: Pergamon.

Paige, R. M. \& Martin, J. M. (1983). Ethical issues and ethics in cross-cultural training. In D. Landis and

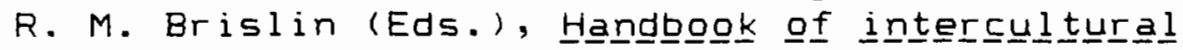

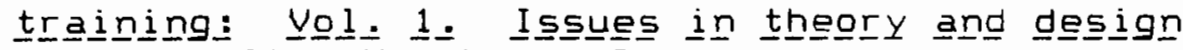
(pp. 36-60). New York: Pergamon. 
Pedersen, P. B. \& Hoopes, D. S. (1975). Research issues in evaluating the objectives of the intercultural communication workshop. In D. S. Hoopes (Ed.),

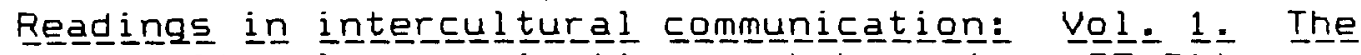

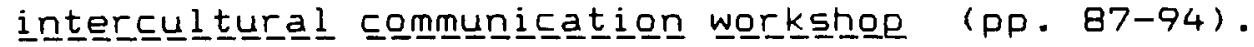
Pittsburgh: The Intercultural Communication Network.

Pool, I. de S. (1965). Effects of cross-national contact on national and international images. In H. Kelman

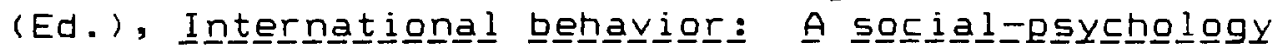
anna 1 ys 1 s (PP. 106-129). New York: Holt, Rinehart, and Winston.

Pusch, M. D. (1981). Cross-cultural training. In G.

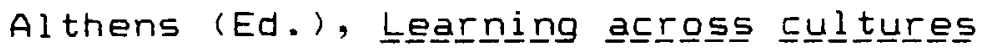
(pP. 73-103). Washington D.C.: Natioñal Association for Foreign Student Affairs.

Ruben, B. D. (1976). Assessing communication competency

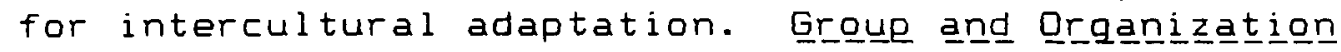
Stㅡ므르토, 르, 220-229.

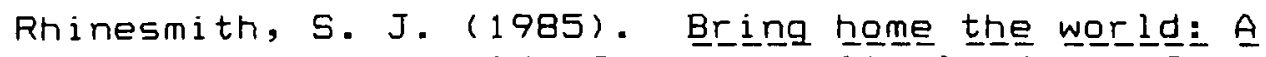

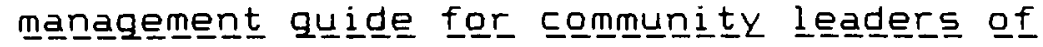


Walker and Company.

Scalzi, D. V. \& Spring, C. (1975). Value of the intercultural workshop on campus. In D. Hoopes (Ed.),

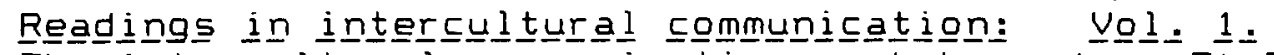


Pittsburgh: The Intercultural Communications Network.

Stewart, E., Danielian, J., \& Foster, R. (1969, May).

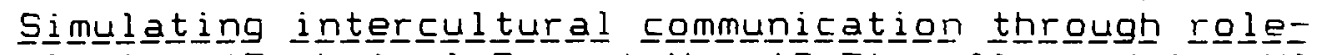
Rlaying (Technical Report No. 69-7). Alexandria, VA: Human Resources Research Organization.

Torrey, E. R. \& Wheeler, G. (1988). Youth exchange homestay study. The United States Information Agency. Washington, D. C.: Bureau of Educational and Cultural Affairs.

Triandis, H.C. (1977, Winter). Theoretical framework for evaluation of cross-cultural training effectiveness.

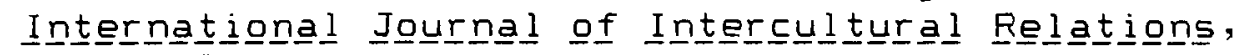
$1,19-45$.

Tucker, F. K., Weaver, R. L., \& Berryman-Fink, C. (1981).

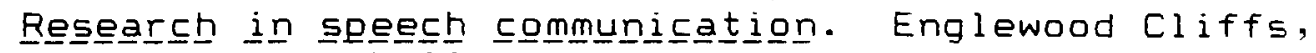
NJ: Prentice-Hall, Inc. 
United States Information Agency. (1983). Guidelines for teenage exchange programs. Washington D. C.: Bureau of Educational and Cultural Affairs, 48, 214. 
APPENDIX A

\section{FISHER-MOORE HOST FAMILY GOALS QUESTIONNAIRE \\ Parent/Guardian}

Part $I$ :

I would like to know how particular goals and objectives apply to your participation as a host family member in an international exchange program. Please answer the following questions as accurately as you can by circling the appropriate number on each scale.

Each question has two parts. Part A asks, "How important was the following goal or objective to your participation in the program?" When answering this part of the question, consider how you felt before your guest's arrival. Part $B$ asks, "To what extent was this goal or objective accomplished?" When answering this part of the question, evaluate how you felt after your guest's departure. Please be sure to answer both Part $A$ and Part $B$ of the question.

Example \#1: As a host family member, how important was it for you:

To establish a long-term relationship with someone from another culture?

A) not important 1234567 very important

To what extent was this accomplished?

B) not at all $122 \quad 345$ 6 7 to a great extent

When answering this question, a host mother considered how she felt before the exchange visit began. She had high hopes for establishing a new and enduring relationship with her guest. Her goal was to continue the relationship even after her guest returned home. Therefore, she answered Part $A$ of the question with a 6 .

After the visit was over, she felt she had established an enduring relationship with her guest. They promised to correspond with each other, and it is possible they might arrange another visit in the future. She felt her goal was accomplished to a great extent, and therefore she answered Part $B$ with a $\underline{\text {. }}$. 
Example \#2: As a host family member, how important was it for you:

To share your family's lifestyle with someone from another culture?

A) not important 1 2 345567 very important

To what extent was this accomplished

B) not at all 12534567 to a great extent

When answering this question, a host father thought about how he felt before the visit began. He had hoped that his foreign guest would want to participate in the many sports acitivities that his family enjoys. His family is warm and out-going, and it was important to him that his visitor share in their active and informal American lifestyle. Therefore, he answered Part $A$ of the question with a .

However, his guest was not particularly athletic and preferred to listen to American music, shop in the local stores and spend quiet time alone. After the visit was over, the host father was disappointed in his guest's lack of interest in the family activities and felt that his goal had hardly been achieved at all. Therefore he marked Part $B$ of the question with a ?.

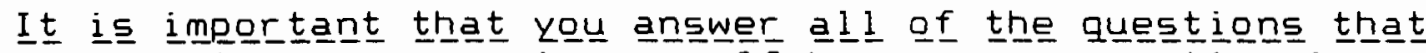
eertain to kour experience. If however, a question is not relevant, leave it unanswered. Example: Question \#8 asks, "How important was it for you to experience being parents because you do not have children of your own?" If you do have children of your own, this question does not apply to your situation and it is not necessary for you to provide an answer.

I appreciate you taking the time to complete this questionnaire. If you have any questions, please feel free to call me at 368-6171 (Nehalem) for clarification.

5

(please continue) 


\section{INTERPERSONAL RELATIONSHIPS}

As a host family member, how important was it for you:

1) To establish a long-term relationship with someone from another culture?
A) not important $123 \quad 345567$ very important
To what extent was this accomplished?
B) not at all $123 \quad 3 \quad 4 \quad 5 \quad 6 \quad 7$ to a great extent

2) To allow your children to interact with people from other cultures?
A) not important $123 \quad 34567$ very important
To what extent was this accomplished?

B) not at all 1234567 to a great extent

3) To interact on a personal level with someone from a culture in which you are specifically interested?

A) not important 12534567 very important

To what extent was this accomplished?

B) not at all 125345 6 7 to a great extent

4) To share your family's lifestyle with someone from another culture?
A) not important 1 ᄅ 34567 very important
To what extent was this accomplished?
B) notatall 1234567 to a great extent

\section{$\underline{I}=$ FAMILYY ISSSUES}

As a host family member, how important was it for you:

5) To bring your family closer together by sharing the hosting experience?
A) not important 1234567 very important
To what extent was this accomplished?
B) not at all 1234567 to a great extent 


\section{FAMILY ISSUESS (continued...)}

6) To strengthen your marriage?
A) not important 12234567 very important

To what extent was this accomplished?

B) not at all 1 ᄅ 3455 b 7 to a great extent

7) To experience being parents because you do not have children of your own?
A) not important 12534567 very important
To what extent was this accomplished?
B) not at all 1234567 to a great extent

8) To experience parenting a girl/boy because you do not have a daughter/son of your own?

A) not important 12534567 very important

To what extent was this accomplished?

B) not at all 12 ( 345 b 7 to a great extent

9) To have another young person around for a while because your own children no longer live at home?
A) not important $12 \begin{array}{llllll}3 & 4 & 5 & 6 & 7 & \text { very important }\end{array}$

To what extent was this accomplished?

B) not at all 1 ᄅ 3455 b 7 to a great extent

10) To provide companionship for your child?

A) not important 1 2 3445677 very important

To what extent was this accomplished?

B) not at all 1 2 3455 b 7 to a great extent

11) To please my child/ren who heard about hosting and wanted to volunteer?

A) not important 12534567 very important

To what extent was this accomplished?

B) not at all 12345 b 7 to a great extent 


\section{GUEESIS AS $A$ REESQURRCE}

As a host family member, how important was it for you:

12) To bring a distinctive individual into your home who may act as a positive role model for your own children?

A) not important $122 \quad 3 \quad 4 \quad 5 \quad 6 \quad 7$ very important

To what extent was this accomplished?

B) not at all 12534567 to a great extent

13) To have a guest who would add to family income?

A) not important 1234567 very important

To what extent was this accomplished?

B) not at all 1234567 to a great extent

14) To provide additional household help?

A) not important $123 \quad 3 \quad 4567$ very important

To what extent was this accomplished?

B) not at all 1234567 to a great extent

15) To provide help in taking care of your own children?

A) not important 1234567 very important

To what extent was this accomplished?

B) not at all 1234567 to a great extent

16) To visit your guest's country in the future? (Acting as a host family may provide contacts in his or her country.) A) not important 1234567 very important

To what extent was this accomplished?

B) not at all 125345 6 7 to a great extent 


\section{PERSONAL FACIORS}

As a host family member, how important was it for you:

17) To further your own personal development?

A) not important 12345567 very important

To what extent was this accomplished?

B) not at all 1 2 3445 b 7 to a great extent

18) To further family members' personal development?

A) not important 1 2 345 b 7 very important

To what extent was this accomplished?

8) not at all $123 \quad 3 \quad 4567$ to a great extent

19) To further your guest's personal development?

A) not important 125345657 very important

To what extent was this accomplished?

B) not at all 12534567 to a great extent

20) To provide this opportunity for someone else because you participated in an exchange program yourself?

A) not important $123 \quad 34567$ very important

To what extent was this accomplished?

B) not at all 125345 6 7 to a great extent

21) To have fun?

A) not important 1234567 very important

To what extent was this accomplished?

B) not at all 12345 6 7 to a great extent

22) To satisfy curiosity about hosting?

A) not important 12234567 very important

To what extent was this accomplished?

B) not at all $123 \quad 34567$ to a great extent

6

(please continue) 


\section{U. EDUCATIONAL OPPQRIUNITIESS}

As a host family member, how important was it for you:

23) To have an educational experience through hosting someone from another culture?

A) not important 12534567 very important To what extent was this accomplished?

B) not at all 12534567 to a great extent

24) To achieve understanding of another culture by bringing someone into your home who knows about that culture?

A) not important $123 \quad 4 \quad 567$ very important

To what extent was this accomplished?

8) not at all 1 2 345 b 7 to a great extent

25) To learn or practice the language of your guest?

A) not important $123 \quad 34567$ very important

To what extent was this accomplished?

B) not at all 12 e $345 \quad 5 \quad 6 \quad 7$ to a great extent

26) To provide your guest with an opportunity for intensive foreign language study?

A) not important 1 ᄅ 345567 very important

To what extent was this accomplished?

B) not at all 12534567 to a great extent

27) To aid in the educational or professional development of your guest?

A) not important $123 \quad 3 \quad 4 \quad 5677$ very important

To what extent was this accomplished?

B) not at all 12345 b 7 to a great extent

28) To sensitize your guest to his/her cultural identity?

A) not important $123 \quad 34567$ very important

To what extent was this accomplished?

B) not at all 125345 b 7 to a great extent (please continue) 
(EDUCEIIONAL OPPORIUNIIIES cont i nuEd. . . )

29) To learn about your own heritage better? (That is, if from French ancestry, having a French guest.)

A) not important 1 ᄅ 344567 very important

To what extent was this accomplished?

B) not at all 12534567 to a great extent

\section{$\underline{V}=$ COMMMUNIIY INQVQLLVEEMENT}

As a host family member, how important was it for you:

30) To share the experience of others in the community who have had a good hosting experience?

A) not important 12534567 very important

To what extent was this accomplished?

B) not at all 125345 6 7 to a great extent

31) To agree to requests from program coordinators who asked you to fill in as a host family?

A) not important $125 \quad 3 \quad 4 \quad 5 \quad 6 \quad 7$ very important

To what extent was this accomplished?

B) not at all 1254567 to a great extent

32) To do something that will allow you to be well thought of in the community?

A) not important 12534567 very important

To what extent was this accomplished?

B) not at all 12534567 to a great extent

8

(please continue) 


\section{DEEVELLPING VALLUES AND AIIIIIUDES}

As a host family member, how important was it for you:

33) To do something different, to accept a risky and unpredictable challenge?

A) not important $123 \quad 34567$ very important

To what extent was this accomplished?

B) not at all 1234567 to a great extent

34) To provide members of your family with the opportunity to change their views of people from other cultures?

A) not important $123 \quad 34567$ very important

To what extent was this accomplished?

B) not at all 1234567 to a great extent

35) To learn about Americans from the perspective of a person from another culture?

A) not important $123 \quad 34567$ very important

To what extent was this accomplished?

B) not at all $123 \quad 3 \quad 4 \quad 5 \quad 6 \quad 7$ to a great extent

36) To show someone from another culture the good things about your values and the American way of life?

A) not important $123 \quad 34567$ very important

To what extent was this accomplished?

B) not at all 1234567 to a great extent

37) To develop friends and supporters for the American way of life by giving persons from other countries a better understanding of our political system?

A) not important $123 \quad 34567$ very important

To what extent was this accomplished?

B) not at all 12345567 to a great extent 


\section{EXXPRESSING YQUUR PHILODSOPHY OF LIFE}

38) To put your religious principles into practice?

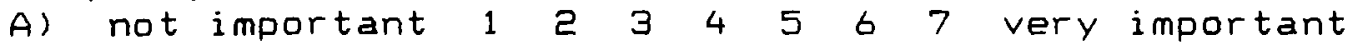

To what extent was this accomplished?

B) not at all $12 \begin{array}{lllllll} & 2 & 4 & 5 & 6 & 7 & \text { to a great extent }\end{array}$

39) To have a personal intercultural experience?

A) not important $1 \quad 2 \quad 3 \quad 4 \quad 56$ 6 7 very important

To what extent was this accomplished?

B) not at all $12 \begin{array}{lllllll}3 & 4 & 5 & 6 & 7 & \text { to a great extent }\end{array}$

40) To increase your intercultural knowledge for the general welfare of humanity?

A) not important $1=3 \quad \begin{array}{llllll} & 2 & 5 & 6 & 7 & \text { very important }\end{array}$

To what extent was this accomplished?

B) not at all $125 \begin{array}{llllll} & 4 & 4 & 5 & 7 & \text { to a great extent }\end{array}$

41) To increase you guest's intercultural knowledge for the general welfare of humanity?

A) not important $1 \quad 2 \quad 3 \quad 4 \quad 5 \quad 6 \quad 7$ very important

To what extent was this accomplished?

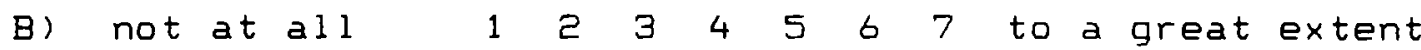

42) To promote international understanding and goodwill among the peoples of the world as a contribution to peace?

A) not important $1 \quad 2 \quad 3 \quad 4 \quad 5 \quad 6 \quad 7$ very important

To what extent was this accomplished?

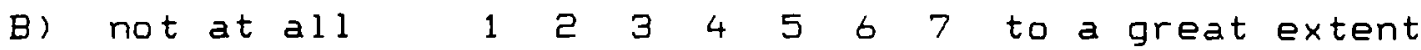

43) To provide an opportunity to an individual from a less developed society who can return and contribute to the economic, social or political development of their own country?

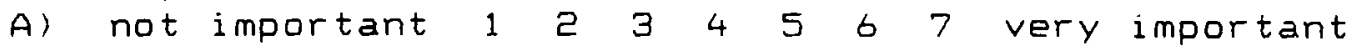
To what extent was this accomplished?
B) not at all $12 \begin{array}{lllllll} & 3 & 4 & 5 & 6 & 7 & \text { to a great extent }\end{array}$ 


\section{Par.t II}

Other than those goals mentioned above, what additional factors, if any, do you regard as relevant to your volunteering as a host family for an international exchange program?

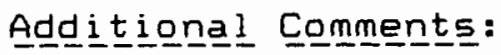


A. Please check one:

$\begin{array}{ll}\text { Host father } & \text { Host mother } \\ \text { Host brother } & \text { Host sister } \\ \text { Other } & \end{array}$

B. Your age:

c. Last year of school completed:

D. Your occupation:

E. Number of children in your family:

Living at home during

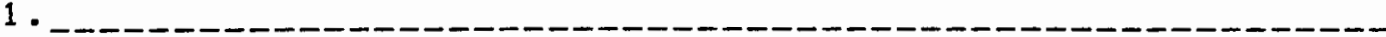
ᄅ. 3. 4. 5.

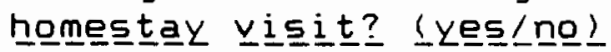

F. How many times have you participated as a host family in an international exchange program lasting three weeks or longer?

From what eountry/countries did your guest/s come?

Based on your previous experience, would you act as a host family again? Yes. No Why? 
G. Was orientation/training made available to you as a host family member? Yes _-..--- No

Did you participate? Yes___-_-_ No

How much time did it involve?

When was it offered?

Before the visit

During the $v i s i t$

After the visit

What was the content of the training/orientation?

H. If you were to host again, and orientation/training were offered, would you participate?

Yes -

Before the visit

During the visit

After the visit

$----+$

What would you like to see included in these sessions?

I. Would you like a copy of the results of this study sent to you?

Yes

No 
APPENDIX B

\section{QUESTIONNAIRE COVER LETTER}

\section{Dear Host Family,}

During the orientation meeting before your Japanese guest arrived on your doorstep, I introduced you to the research that I have been conducting. Now, I would like to invite you to participate.

Your participation simply requires you as a host parent to individually complete the enclosed questionnaire. Please do not confer with your spouse, children, or roommate. I wish to obtain as many responses as possible and each of your individual goals are significant. I am asking only 50 families to participate: therefore complete data from each of you is essential to the usefulness of the study.

I assure you complete anonymity. I will not ask you to identify yourself. The number on the questionnaire is only for follow-up purposes. Your responses will in no way affect your future participation in an exchange program.

The purpose of this research is to identify goals and objectives that are regarded as significant by host families. This information will be useful in developing orientation and training programs that will meet the needs of both visitors and hosts. Research has never before addressed the host families' goals.

If you have any questions, please call me at 297-3917 and I will return your call as soon as I receive your message. (The Nehalem phone number on the questionnaire is my coresearcher's). If you experience problems that are the result of your participation in this study, please contact the secretary of the Human Subjects Research and Review Committee, $303 \mathrm{Cramer} \mathrm{Hall,} \mathrm{Portland} \mathrm{State} \mathrm{University} \mathrm{(503)}$ $464-3417$. 
You will find a stamped, pre-addressed envelope enclosed. I will appreciate receiving your completed questionnaire by August 31 .

I would like to thank you in advance for your assistance with this project.

sincerely,

Jan Dehlsch laeger

INTRAX Program Coordinator 